University of Wollongong

Research Online

Faculty of Engineering and Information

Faculty of Engineering and Information

Sciences - Papers: Part B

Sciences

2019

Energy and exergy analysis of a desiccant cooling system integrated with thermal energy storage and photovoltaic/thermal-solar air collectors

Zhenjun Ma

University of Wollongong, zhenjun@uow.edu.au

Haoshan Ren

University of Wollongong, hr681@uowmail.edu.au

Zhongwei Sun

China Resources Power Investment Co. Ltd

Follow this and additional works at: https://ro.uow.edu.au/eispapers1

Part of the Engineering Commons, and the Science and Technology Studies Commons

Research Online is the open access institutional repository for the University of Wollongong. For further information contact the UOW Library: research-pubs@uow.edu.au 


\title{
Energy and exergy analysis of a desiccant cooling system integrated with thermal energy storage and photovoltaic/thermal-solar air collectors
}

\author{
Abstract \\ This paper presents an energy and exergy analysis of a desiccant cooling system integrated with an air- \\ based thermal energy storage (TES) unit using phase change materials (PCMs) and a photovoltaic/ \\ thermal-solar air collector (PV/T-SAC). The PV/T-SAC was used to generate thermal energy for desiccant \\ wheel regeneration and space heating, and the TES was used to solve the mismatch between thermal \\ energy supply and demand. The performance of this system was evaluated using a simulation system \\ developed using TRNSYS. The effects of several key parameters on solar thermal contribution, specific \\ net electricity generation, and the exergy destructions of individual components and overall system were \\ investigated. It was found that the system exergy destruction was mainly resulted by the PV/T-SAC. Both \\ the exergy performance and energy performance of this system were significantly influenced by the \\ length and PV factor of the PV/T-SAC used. The results obtained from this study could be potentially used \\ to guide the optimal design of desiccant cooling systems integrated with thermal energy storage and \\ solar energy systems.

\section{Disciplines} \\ Engineering | Science and Technology Studies

\section{Publication Details} \\ Ma, Z., Ren, H. \& Sun, Z. (2019). Energy and exergy analysis of a desiccant cooling system integrated with \\ thermal energy storage and photovoltaic/thermal-solar air collectors. Science and Technology for the \\ Built Environment, Online First 1-16.
}




\title{
Energy and exergy analysis of a desiccant cooling system integrated with thermal energy storage and photovoltaic/thermal- solar air collectors
}

\begin{abstract}
This paper presents an energy and exergy analysis of a desiccant cooling system integrated with an air-based thermal energy storage (TES) unit using phase change materials (PCMs) and a photovoltaic/thermal-solar air collector (PV/T-SAC). The PV/T-SAC was used to generate thermal energy for desiccant wheel regeneration and space heating, and the TES was used to solve the mismatch between thermal energy supply and demand. The performance of this system was evaluated using a simulation system developed using TRNSYS. The effects of several key parameters on solar thermal contribution, specific net electricity generation, and the exergy destructions of individual components and overall system were investigated. It was found that the system exergy destruction was mainly resulted by the PV/T-SAC. Both the exergy performance and energy performance of this system were significantly influenced by the length and PV factor of the PV/T-SAC used. The results obtained from this study could be potentially used to guide the optimal design of desiccant cooling systems integrated with thermal energy storage and solar energy systems.
\end{abstract}

Keywords: Energy analysis; exergy analysis; performance simulation; desiccant cooling; thermal energy storage. 


\section{Introduction}

The demand for better indoor environment and a dramatic increase in energy consumption of air conditioning systems are among the critical challenges that should be tackled in the coming decades. Although various low carbon energy technologies have been discussed (Masy et al. 2015; Lin et al. 2016; Wang et al. 2017), desiccant wheel cooling (DWC) has been extensively investigated due to the fact that it can be driven by low-grade thermal energy (Fong and Lee 2018; Zhang et al. 2017). Using solar energy to drive DWC has been considered as a promising approach to developing renewable cooling systems (Wu et al. 2018; Nciri et al. 2013). Chaudhary et al. (2018) examined the performance of a DWC system using solar water heaters assisted by an electric heater. The experiment results showed that the thermal coefficient of performance of this system varied from 0.65 to 1.17 when the supply air temperature varied from $14{ }^{\circ} \mathrm{C}$ to $22{ }^{\circ} \mathrm{C}$, and the solar thermal contribution (STC) of this system was around $70 \%$. The annual performance of a DWC system using heated air from solar air heaters for the desiccant wheel (DW) regeneration was investigated by Firozjaei et al. (2015). The results showed that this system could cover $54 \%$ and $48 \%$ of the cooling demand of an office building under the weather conditions of north and south of Iran, respectively. The performance of a desiccant-assisted cooling system using solar thermal energy to regenerate DW and geothermal energy for sensible cooling was investigated by Speerforck et al. (2017). It was found that approximately half of the electricity consumption of the system was saved under the weather conditions of Chicago, New York, and Washington D.C, when comparing to that of using a vapor compression air conditioning system. Subiantoro (2019) investigated the feasibility of using a vapor compression air-conditioner integrated with a desiccant wheel for space cooling 
of a small-scale household under tropic weather conditions. The results showed that a higher cost saving by using this integrated system instead of using the vapor compression airconditioner only was achieved under higher cooling capacity, air change rate, usage of the airconditioner and electricity price. Tu and Wang (2017) investigated the performance of a unitary solid desiccant air conditioner which was essentially an air-conditioner using desiccant-coated heat exchangers as the evaporator and condenser. The results showed that the coefficient of performance of this system was improved significantly, as compared to a conventional airconditioner, and the improvement was more significant under high latent load conditions.

Thermal energy storage (TES) using phase change materials (PCMs) is an ideal solution to overcome the discrepancy between thermal energy demand and thermal energy generation from solar systems. PCMs have attracted increasing research interest in developing highperformance buildings and highly efficient building energy systems (Lin et al. 2019; Ma et al. 2016; Zeinelabdein et al. 2018). Lu et al. (2019) investigated the performance of a PCM TES unit integrated with a solar water heating system. The PCMs with high latent capacities were recommended to improve the thermal performance of this system. Papachristou et al. (2018) deployed a model predictive control (MPC) strategy to optimize the performance of a wallintegrated PCM TES unit for load shifting. The results showed that the peak power demand reduction for space heating was achieved in the first and second test days. However, a negligible peak power demand reduction was observed in the third test day due to the MPC used a different temperature setting profile to maintain the indoor thermal comfort. A DWC system using a TES unit and a photovoltaic/thermal-solar air collector (PV/T-SAC) was recently studied (Ren et al. 2019). The result showed that using the PV/T-SAC and TES could potentially take the system 
off the grid if it is properly sized.

Exergy analysis has been considered as an effective approach to evaluating the performance of desiccant cooling systems and PCM TES, as the exergy analysis could provide information on the quality of energy generated and consumed (Enteria et al. 2013; Sheng et al. 2015; Abbassi et al. 2017; Zhao et al. 2018). The energy performance and exergy performance of a DWC system were investigated by Enteria et al. (2013). The DW was regenerated using a solar water heater integrated with a water storage tank with the assistance of a water-to-air heat exchanger. The exergy analysis showed that the solar water heater can cover $86.4 \%$ of thermal energy consumption, while the highest exergy destruction and energy loss were also contributed by the solar water heater. Abbassi et al. (2017) compared the exergy performance of a solar desiccant system using different configurations. It was found that two-stage systems using two desiccant wheels for air dehumidification showed higher energy consumption, higher exergy destruction, higher initial investment, and higher maintenance cost, as compared to the single-stage systems. Moreover, the linear parabolic collector used for DW regeneration contributed to the largest part of the exergy destruction in each configuration investigated. In a more recent study, Caliskan et al. (2019) evaluated the performance of a DWC system based on energy, exergy, and sustainability analyses. The results showed that the exergy efficiency of the DW should be first improved among the three main components including the DW, sensible heat wheel, and regenerative evaporative cooler, in order to enhance the overall system efficiency. Zhao et al. (2018) investigated the exergy performance of a PCM TES unit using a three-stage configuration, in which PCMs with three different melting temperatures were used in each stage respectively. It was shown that the charging efficiency in terms of energy, exergy, and entransy 
of each stage increased with the increase of the inlet temperature of the heat transfer fluid (HTF), while the influence of the HTF flow rate on the efficiency varied for different stages. However, the energy and exergy analysis of DWC systems with on-site electricity and thermal energy generation and PCM TES was rarely found, and the relevant studies may provide useful information for further improvement of such systems.

This paper presents energy analysis and exergy analysis of a DWC system integrated with a PCM TES unit and a PV/T-SAC system (named as DWC-TES-PV/T-SAC hereafter) based on annual simulation results. The energy performance of the system was evaluated in terms of specific net electricity generation (SNEG) and STC, and the exergy performance was evaluated using the exergy destruction of individual components and the overall system. The influences of several key design parameters on the energy and exergy performance of the system were investigated. The key design parameters considered included total length of the PV/T-SAC, PV factor of the PV/T-SAC (i.e. length of the PV/T to the total length of the PV/T-SAC), air channel depth of the PV/T-SAC, thickness of the desiccant wheel, total amount of the PCM used, air channel depth of the PCM TES, and phase change temperature of the PCM. Lastly, the interactions among the key design parameters were investigated based on the response surface method (RSM).

\section{System description and modeling}

\section{System description}

The schematic of the DWC-TES-PV/T-SAC system is presented in Fig. 1. The DWC system mainly consists of a DW, a heat recovery unit (HRU), an indirect evaporative cooler 
(IEC), and an electric heater (EH). The PV/T-SAC was adopted to generate thermal energy (i.e. heated air) and electricity. The thermal energy was used to regenerate the DW and for space heating during cooling and heating seasons, respectively. The electricity was used to power the EH and fans. The TES unit using PCM was used to store the thermal energy produced by the PV/T-SAC, which could be used for DW regeneration or for space heating when the solar radiation was low or there is no solar radiation. During the cooling season, the process air was first dehumidified by the DW, and then cooled by the HRU and IEC. A bypass of the return air was used for the DW when the temperature of the outlet air from the PV/T-SAC was above the required regeneration temperature, in order to control the humidity ratio of the process air. The regeneration air flow rate was equal to the process air flow rate, which was determined based on the building cooling demand. The supply air temperature was controlled by modulating the bypass ratio of the supply air through the IEC. The supply air humidity ratio was controlled by varying the inlet temperature of the regeneration air of the DW. During the heating season, the fresh air or the return air was heated by the PV/T-SAC or the TES unit dependent on the operation mode used, and was then used for space heating.

The DWC-TES-PV/T-SAC system can operate with three different modes (I, II, and III) during heating and cooling seasons, respectively, as summarized in Table 1. Under Mode I, the ambient air was heated by the PV/T-SAC. A portion of the air flow from the PV/T-SAC was directly used to regenerate DW and for space heating during the cooling and heating seasons respectively, and the rest was directed into the TES to charge the PCM or exhausted to ambient dependent on the average surface temperature of the PCM bricks. Under Mode II, the rated PV/T-SAC air flow rate was used. The ambient air was heated by the PV/T-SAC and was then 
used to charge the TES unit or exhausted to ambient dependent on the outlet air temperature of the PV/T-SAC and the average surface temperature of the PCM bricks. Under Mode III, the TES unit was discharged to provide thermal energy for DW regeneration during the cooling season and for space heating during the heating season. During the cooling season, the ambient air was first heated by the HRU and then by the TES unit before it was used to regenerate the DW. During the heating season, the return air instead of ambient air was used for space heating to improve the system thermal efficiency. Over-heating of the air was avoided by using a bypass for the TES unit. The electric heater was used as an auxiliary heating device in Modes I \& III. System modeling

This system was modeled and simulated using TRNSYS (Klein et al. 2010), as shown in Fig. 2. The PV/T-SAC was simulated using a dynamic model developed based on the finite volume method with a Crank Nicolson scheme (Fan et al. 2017). The governing equation of the air flow of the PV/T-SAC is given in Eq. (1). The pressure drop of the PV/T-SAC was calculated via an equivalent hydronic resistance network. The PCM TES unit was simulated using a dynamic model developed by Ren et al. (2018) and the governing equation for the energy balance of the PCM is provided in Eq. (2). The pressure drop across the TES unit was calculated using the same method as that used for the PV/T-SAC. The DW was modeled based on the method developed by Kang et al. (2015), in which the outlet temperature and humidity ratio of the process air were predicted using Eqs. (3) and (4), respectively. The pressure drops across the DW was calculated using the equations provided by De Antonellis et al. (2010). The IEC was modeled using a one-dimensional model developed by Chen et al. (2016) and the governing equation for the supply air is given in Eq. (5), and the pressure drop across the IEC was 
determined according to Chen et al. (2017). The HRU was modeled using the same method as that used by TRNSYS component Type 760. The energy consumptions of the EH and fan were determined using Eqs. (6) and (7), respectively.

$$
\begin{aligned}
& C_{p, a} \rho_{a} \Delta x\left(W_{d} H_{f i n}\right) \frac{\partial T_{a, i}}{\partial t}+C_{p, a} \dot{m}_{a} \Delta x \frac{\partial T_{a, i}}{\partial x}=h_{c, a p-a} A\left(T_{a p, i}-T_{a, i}\right)+h_{c, b p-a} A\left(T_{b p, i}-\right. \\
& \left.T_{a, i}\right)+2 h_{c, f \text { in }-a} A_{\text {fin }}\left(T_{f i n, i}-T_{a, i}\right) \\
& \rho_{P C M} \frac{\partial h_{P C M}}{\partial t}=k_{P C M} \frac{\partial^{2} T_{P C M}}{\partial y^{2}} \\
& T_{p r o, a, o u t}=T_{\text {pro,a,in }}+\frac{A_{1} \exp \left(-\lambda_{1} \tau\right)+A_{2} \exp \left(-\lambda_{2} \tau\right)}{1 / N_{D W}+0.5}\left(T_{\text {ideal }}-T_{\text {pro,a,in }}\right) \\
& W_{\text {pro,a,out }}=W_{\text {pro,a,in }}+\frac{B_{1} \exp \left(-\lambda_{1} \tau\right)-B_{2} \exp \left(-\lambda_{2} \tau\right)}{1 / N_{D W}+0.5}\left(W_{\text {pro, }, \text { in }}-W_{\text {ideal }}\right) \\
& h_{c}\left(T_{\text {sup }}-T_{\text {wall }}\right) d A=C_{p, a} \dot{m}_{\text {sup }, a} d T_{\text {sup }} \\
& P_{E H}=\dot{m}_{\text {reg,a }} C_{p, a}\left(T_{r e g, a}-T_{\text {before }, E H, a}\right) \\
& P_{\text {fan }}=\frac{V \Delta p}{\eta_{\text {fan }}}
\end{aligned}
$$

where $W_{d}$ is the width of the PV/T-SAC, $\Delta x$ is the length of each control volume, $H_{\text {fin }}$ is the fin height, $T$ is the temperature, $\rho$ is the density, $C_{p}$ is the specific heat capacity, $\dot{m}$ is the mass flow rate, $h_{c}$ is the forced convection coefficient, $A$ is the area, $A_{\text {fin }}$ is the fin surface area, $k$ is the thermal conductivity, $h$ is the enthalpy, $W$ is the humidity ratio, $P$ is the power, $V$ is the volumetric air flow rate, $\Delta p$ is the pressure drop, $\eta_{f a n}$ is the fan efficiency, and the subscripts $a p$, bp, pro, reg, sup, $E H, a$, in, and out indicate absorber plate, bottom plate, process, regeneration, supply, electric heater, air, inlet, and outlet, respectively. The details of the parameters used in Eqs. (3) and (4) can be found in Kang et al. (2015).

\section{Energy and exergy analysis}

The energy performance of the DWC-TES-PV/T-SAC system was evaluated using two 
performance indicators, i.e. STC and SNEG. STC was defined as the total amount of thermal energy provided by the PV/T-SAC and TES unit for DW regeneration and for space heating, divided by the total thermal energy demand for DW regeneration and space heating and is calculated using Eq. (8). SNEG is the difference between the electricity generated by the PV/TSAC and the electricity consumption during the whole simulation period, divided by the total area of the PV panels used and is calculated using Eq. (9).

$S T C=\frac{\int_{t_{1}}^{t_{2}}\left[\dot{m}_{\text {reg }, a, i} C_{p, a}\left(T_{\text {before }, a, E H, i}-T_{a, i n, i}\right)+\dot{m}_{\text {sup }, a, \text { heat }, i} C_{p, a}\left(T_{\text {before }, a, E H, i}-T_{a, i n, i}\right)\right] d t}{\int_{t_{1}}^{t_{2}}\left[\dot{m}_{r e g, a, i} C_{p, a}\left(T_{\text {reg, }, a, i}-T_{a, i n, i}\right)+Q_{\text {heat }, i}\right] d t}$

$S N E G=\frac{\int_{t_{1}}^{t_{2}}\left(P_{p v, i}-P_{f a n, i}-P_{E H, i}\right) d t}{A_{p v}}$

where $T_{a \text {,in }}$ is the inlet air temperature of the PV/T-SAC or the PCM TES unit dependent on the operation mode used, $Q_{\text {heat }}$ is the heating load, $P_{p v}$ is the power generation of the PV panels, $P_{f a n}$ and $P_{E H}$ are the power consumptions of the fan and EH respectively, $A_{p v}$ is the area of the PV panel, and $t_{1}$ and $t_{2}$ are the start time and end time, respectively.

The exergy performance of the DWC-TES-PV/T-SAC system was evaluated based on the exergy destruction of the whole system and exergy destructions of individual components including PV/T-SAC, PCM TES unit, DW, HRU, IEC, fan, and EH. The exergy destruction indicates the irreversibility of a thermodynamic process, which should be minimized in order to improve the exergy performance of the process. The exergy destruction rate of the PV/TSAC was evaluated using the technical boundary approach, which has been widely used to evaluate the exergy performance of solar thermal collectors and PV/T systems (Torio et al. 2009). The major assumption of the technical boundary approach was that the exergy of the solar radiation was considered as thermal radiation at the sun temperature and the conversion of solar radiation into thermal energy and electricity was included in the analysis (Torio et al. 
2009). Based on the technical boundary approach, the exergy destruction rate $\left(\dot{E x_{\text {dest }}}\right)$ of the PV/T-SAC could be determined using Eq. (10), in which electricity was considered as pure exergy (Bejan 2016). The exergy of solar radiation (Ex $x_{\text {solar }}$ ) could be calculated using Eq. (11) (Petela 2003; Chow et al. 2009). The specific exergy of air (exa) was calculated using Eq. (12) (Bejan 2016) by taking thermal exergy, mechanical exergy, and chemical exergy into account.

$$
\begin{aligned}
& \dot{E} x_{d e s t, P S}=\dot{E} x_{s o l a r, P S}+\dot{m}_{a, P S}\left(e x_{a, P S, i n}-e x_{a, P S, o u t}\right)-\dot{E} x_{l o s s, P S}-P_{p v}
\end{aligned}
$$

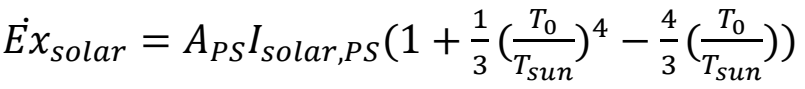

$$
\begin{aligned}
& e x_{a}=\left(C_{p, a}+W_{a} C_{p, v}\right) T_{0}\left(\frac{T}{T_{0}}-1-\ln \frac{T}{T_{0}}\right)+\left(1+1.608 W_{a}\right) R_{a} T_{0} \ln \frac{p}{p_{0}}+R_{a} T_{0}[(1+ \\
& \left.\left.1.608 W_{a}\right) \ln \frac{1+1.608 W_{a, 0}}{1+1.608 W_{a}}+1.608 W_{a} \ln \frac{W_{a}}{W_{0}}\right]
\end{aligned}
$$

where $E x_{\text {loss }}$ is the exergy loss rate from the component to ambient, $I_{\text {solar, }}$ is the solar radiation, $T_{\text {sun }}$ is the sun temperature which is generally considered as 6,000 $\mathrm{K}$ (Chow et al. 2009; Gunerhan and Hepbasli 2007), $R$ is the gas constant, $p$ is the pressure, and the subscripts $P S$, $p v$, and $v$ indicate PV/T-SAC, PV panel, and vapor respectively, $\left(T_{0}, W_{0}, p_{0}\right)$ represents the dead state of the exergy analysis, which were the ambient air temperature, humidity ratio of the saturated air at $T_{0}$, and atmospheric pressure, respectively (Lin et al. 2018).

The exergy destruction rates of the DW, IEC, and EH were evaluated using Eq. (13) (Tu et al. 2015), Eq. (14) (Lin et al. 2018), and Eq. (15) (Hürdoğan et al. 2011), respectively. The specific exergy of water was determined using Eq. (16) (Bejan 2016). The exergy destruction rates of the HRU and fans were evaluated using similar methods as those of the DW and EH, respectively. The exergy destruction rate of the TES unit during the charging process was evaluated using Eq. (17) and that during the discharging process can be developed in a similar way (Jegadheeswaran et al. 2010; Dincer and Rosen 2002). The exergy storage rate of the PCM 
(Ex $x_{\text {store }, P C M}$ ) was determined using Eq. (18) (Jegadheeswaran et al. 2010) and its exergy extract rate was determined in the similar way.

$$
\begin{aligned}
& \dot{E} x_{d e s t, D W}=\dot{m}_{a, p r o}\left(e x_{a, p r o, i n}-e x_{a, p r o, o u t}\right)+\dot{m}_{a, r e g}\left(e x_{a, r e g, i n}-e x_{a, r e g, o u t}\right) \\
& \dot{E} x_{d e s t, I E C}=\dot{m}_{a, I E C, p r i, i n} e x_{a, I E C, p r i, i n}-\dot{m}_{a, I E C, p r i, o u t} e x_{a, I E C, \text { pri,out }}- \\
& \dot{m}_{a, I E C, \text { sec }, \text { out }} e x_{a, I E C, \text { sec }, o u t}+\dot{m}_{\text {evap, }, I E C} e x_{w, I E C, \text { in }} \\
& \dot{E x_{d e s t, E H}}=\dot{m}_{a, E H}\left(e x_{a, E H, i n}-e x_{a, E H, o u t}\right)+P_{E H} \\
& e x_{w}=h_{w}(T)-h_{v}\left(T_{0}\right)-T_{0} s_{w}(T)+T_{0} s_{v}\left(T_{0}\right)+\left[p-p_{s a t}(T)\right] v_{w}(T)-R_{v} T_{0} \ln \left(R H_{0}\right) \\
& \dot{E} x_{d e s t, P C M, \text { char }}=\dot{m}_{a, P C M}\left(e x_{a, P C M, \text { in }}-e x_{a, P C M, o u t}\right)-\dot{E} x_{s t o r e, P C M}-\dot{E} x_{l o s s, P C M} \\
& \dot{E} x_{\text {store }, P C M}=\left(\dot{Q}_{\text {char }}-\dot{Q}_{\text {loss }}\right)\left(1-\frac{T_{0}}{T_{P C M, a v e}}\right)
\end{aligned}
$$

where $s$ is the entropy, $v$ is the specific volume, $\dot{Q}_{c h a r}$ is the thermal energy charged into the TES unit, $\dot{Q}_{\text {loss }}$ is the thermal energy loss from the TES unit to ambient, $R H_{0}$ is the relative humidity of air at the dead state, and the subscripts pri, sec, w, evap, sat, char, and ave indicate primary, secondary, water, evaporation, saturation, charging, and average respectively, and $\dot{m}_{\text {evap,w,IEC }}$ indicates the evaporation rate of water in the secondary air channel.

The exergy destructions of the individual components during the whole simulation period were obtained by integrating the corresponding exergy destruction rate over the simulation time. The total exergy destruction of the DWC-TES-PV/T-SAC system was the sum of the exergy destructions of the PV/T-SAC, PCM TES unit, DW, HRU, IEC, fan, and EH. The exergy destruction of the duct was not considered as it has a negligible influence on the exergy destruction of the DWC-TES-PV/T-SAC system.

\section{Results and discussion}

\section{Model validation}


The experimental data reported by Yamaguchi and Saito (2013) and Riangvilaikul et al. (2010) were used to validate the models of the DW and IEC respectively, and the results are presented in Fig. 3. The simulated outlet temperature and humidity ratio of the process air from the DW agreed well with the experimental data. The average deviations between the simulated results and the experimental data were $2.0 \%$ for the outlet air temperature (Fig. 3a) and 5.5\% for the outlet air humidity ratio (Fig. 3b). The simulated temperature difference between the inlet and outlet air of the IEC also agreed with that of the experiments and the deviations were within $\pm 10 \%$ (Fig. 3c).

Setup of the simulations

In this study, the DWC-TES-PV/T-SAC system was assumed to be used for space cooling and heating of a house which previously participated in a Solar Decathlon (SD) competition. The total air-conditioned area of the house was $68 \mathrm{~m}^{2}$. The house was assumed to be conditioned on a 24-hour basis. The performance simulation was implemented for a typical year. The International Weather for Energy Calculation (IWEC) data of Brisbane (Australia) was used as the weather data. Fig. 4 shows the cooling and heating load of the SD house simulated over the course of the year.

The energy performance and exergy performance of the DWC-TES-PV/T-SAC system were evaluated through investigating the influence of seven key design parameters on the SNEG, STC, and the exergy destructions of individual components and the overall system. The seven key design parameters considered were the total length of the PV/T-SAC, PV factor, air channel depth of the PV/T-SAC, DW thickness, total amount of the PCM used which was controlled by varying the number of PCM layers, air channel depth of the PCM TES unit, and 
PCM phase change temperature. The number of PCM layers was considered as a discrete variable while the others were the continuous variables. These design parameters were selected based on the results reported in the previous studies (Ren et al. 2019; Dolado et al. 2011; Fan et al. 2018). The interactions among these parameters were further investigated using the RSM (Montgomery 2012). To formulate the simulation plan of the parametric study, a baseline design was established, and each key design parameter was changed in each simulation while maintaining the other parameters constant as the same values used in the baseline design. The values of the parameters used in the baseline design and their variation ranges used are summarized in Table 2, which were determined based on the trial tests. An enthalpytemperature curve function reported by Mazo et al. (2015) was used to facilitate the change of the phase change temperature. The PCM heat storage capacity was determined based on the manufacturing data (Rubitherm 2018). Paraffin-based PCM was used in this study due to its stable thermal performance. The other parameters of the DWC-TES-PV/T-SAC system are summarized in Table 3, which were determined based on the previous studies (Ren et al. 2019; Chen et al. 2018; Dolado et al. 2011). It is worthwhile to note that the rotation speed of the DW increased when decreasing the DW thickness in order to maintain the required dehumidification capacity of the DW (Yamaguchi and Saito 2013). A higher PV/T-SAC rated air flow rate was used during the heating season than that used during the cooling season, to avoid overheating of the supply air.

To investigate the influence of the interactions among the seven design parameters on the SNEG, STC, and total exergy destruction of the system, another simulation plan was designed and implemented based on the RSM. The Face Centered Central Composite Design 
(Montgomery 2012) with three levels for each parameter was used to formulate the simulation plan, resulting in 79 simulation cases, based on the variation ranges of the design parameters presented in Table 2. Quadratic equations were used to establish the response surface models of the total exergy destruction, SNEG, and STC by the stepwise regression method.

Results from the parametric study

The simulation exercises were implemented using the simulation system developed using TRNSYS. The exergy destructions of the DW, HRU, IEC, TES unit, EH, and fan are presented in Fig. 5, while the total exergy destruction of the whole system and the exergy destruction of the PV/T-SAC are presented in Fig. 6. It is worthwhile to note that the exergy destruction of the PV/T-SAC contributed the majority of the exergy destruction of the system due to the fact that the high-quality solar radiation was converted into low-grade thermal energy and a relatively small amount of electricity. Therefore, the exergy destruction of the PV/T-SAC was separately presented in Fig. 6 in order to clearly show the difference among different components. It can be observed that the EH, fan, and TES contributed substantial amounts of the exergy destruction, while the contribution from the IEC can be negligible (Fig. 5). The exergy destructions of the EH and TES decreased and increased respectively with the increase in the PV/T-SAC length (Fig. 5a). This can be explained by the increased outlet air temperature due to the increased PV/T-SAC length. The exergy destruction of the TES slightly decreased while those of the fan and EH slightly increased when increasing the PV factor (Fig. 5b). The exergy destruction of the fan decreased significantly while those of the TES and EH slightly decreased and increased with the increase of the PV/T-SAC air channel depth (Fig. 5c). The exergy destruction of the DW and EH decreased with the increase of the DW thickness (Fig. 5d), as the required 
regeneration temperature of the DW was decreased with the increase of the heat and mass transfer area. The exergy destruction of the HRU also decreased as the temperature of the process air at the inlet of the HRU was decreased. However, the exergy destruction of the fan increased due to the increased air pressure drop across the DW. The exergy destruction of the TES increased with the increase of the amount of the PCM used while that of the EH was substantially decreased (Fig. 5e). The exergy destruction of the fan and the TES both decreased while that of the EH increased with the increase of the air channel depth of the TES unit (Fig. 5f). The total exergy destruction of these six components first decreased and then increased with the increase of the PCM phase change temperature (Fig. 5g), which was mainly resulted by the variation in the exergy destruction from the EH.

The results in Fig. 6a showed that the PV/T-SAC contributed a major fraction of the exergy destruction of the system and the contributions from the other components were insignificant. The exergy destruction of the whole DWC-TES-PV/T-SAC system and the exergy destruction of the PV/T-SAC almost linearly increased when the PV/T-SAC length was increased. Similar results were also found in the previous studies (Torio and Schmidt 2008; Torio et al. 2009), in which it was indicated that replacing solar systems by fossil fuels could improve the exergy performance of a heating and cooling system, and the solar collectors were the largest contributor to the exergy destruction of the whole system. The exergy destructions of the whole system and the PV/T-SAC both decreased with the increase of the PV factor as the electricity generation was increased (Fig. 6b). The exergy destruction of the PV/T-SAC increased with the increase of the air channel depth as presented in Fig. 6c due to the decrease in thermal efficiency. However, there was an optimal value approximately at the PV/T-SAC air channel depth of 0.016 
m, which minimized the total system exergy destruction. Similar results were also observed in Fig. 6d for the DW thickness while the influence of the DW thickness on the exergy destruction of the PV/T-SAC was insignificant. The exergy destruction of the PV/T-SAC remained constant of 47,491 kWh when varying the PCM phase change temperature, the amount of the PCM used, and the PCM TES unit air channel depth. The total exergy destruction of the whole system was therefore not presented in Fig. 6 as it can be easily derived from the results presented in Fig. 5.

The results of the energy analysis in terms of the SNEG and STC are presented in Fig. 7, and the electricity consumptions of the $\mathrm{EH}$ and fan are presented in Fig. 8. It can be seen that the STC and SNEG increased while the increasing rate was reduced when increasing the PV/TSAC length (Fig. 7a). The increase of the STC and SNEG could be explained by the reduced power consumption of the EH as presented in Fig. 8a. From Fig. 7b, it can be seen that the SNEG first increased and then decreased while the STC was slightly reduced with the increase of the PV factor. The STC contribution was maintained at a relatively high level. The fan power consumption was not clearly influenced by the PV factor while the EH power consumption increased when the PV factor was increased (Fig. 8b). The SNEG first increased and then decreased with the increase of the PV/T-SAC air channel depth (Fig. 7c), as the power consumptions of the fan and EH decreased and increased respectively with different decreasing rate and increasing rate (Fig. 8c). The STC decreased with the increase of the PV/T-SAC air channel depth due to the decreased thermal efficiency of the PV/T-SAC. Similar trends of the SNEG, STC, and the power consumptions of EH and fan were also observed when increasing air channel depth of the TES unit (Figs. $7 \mathrm{f}$ and 8f). The SNEG and STC both increased with the increase of the DW thickness while the SNEG slightly decreased when the DW thickness was 
above $0.35 \mathrm{~m}$ (Fig. 7d), which could be explained by the increased fan power consumption (Fig. 8d). The SNEG and STC both increased with the increase in the number of PCM layers (Fig. 7e), as the power consumption of the EH was substantially decreased (Fig. 8e). The SNEG and STC both first increased and then decreased with the increase of the phase change temperature (Fig. 7g), which could be explained by the opposite variation trend of the power consumption of the EH (Fig. 8g).

Based on the above results, it can be observed that the variation trends of the exergy destruction of the EH and fan (Fig. 5) agreed well with the power consumptions of the EH and fan (Fig. 8), respectively. This is because the exergy destruction was mainly resulted by the conversion of high-quality electricity into thermal energy in the EH and into kinematic energy in the fan. The energy performance of the system can be improved when using a larger amount of the PCM used (Fig. 7e). However, a larger amount of the PCM will result in slightly higher exergy destruction of the TES (Fig. 5e). Therefore, an optimal amount of the PCM to be used should be determined based on the trade-off between energy performance and exergy performance. The energy analysis results showed that using a larger PV/T-SAC could improve SNEG and STC. However, the exergy analysis results showed that the PV/T-SAC contributed the largest fraction of the exergy destruction of the system and using a larger PV/T-SAC will result in higher exergy destruction.

Results from the response surface simulation plan

Based on the annual performance data, the response surface models were developed to predict the SNEG, STC, and total exergy destruction of the system using the RSM. $\mathrm{R}^{2}$ of the models developed for the SNEG, STC, and total exergy destruction were $0.9809,0.9923$, and 
0.9998, respectively. The details of the models can be found in the Appendix. The variations of the SNEG when simultaneously changing two parameters of the seven key design parameters while maintaining the other five parameters the same as those used in the baseline case, are presented in Fig. 9. It is noted that this figure was developed using the data generated from the response surface model for the SNEG. Under a given PV/T-SAC length, the SNEG decreased with the decrease of the PV factor, however, the decreasing rate of the SNEG was reduced when increasing the PV/T-SAC length (Fig. 9a). Similar trends of the SNEG were also observed when varying the number of PCM layers and the PV/T-SAC length (Fig. 9e). The SNEG increased with the increase of the DW thickness when the PV/T-SAC length was $6 \mathrm{~m}$. However, when the PV/T-SAC length was increased to $10 \mathrm{~m}$, the SNEG first increased and then decreased with the increase of the DW thickness (Fig. 9c). The results from Fig. 9a-f showed that the PV/T-SAC length was generally the-larger-the-better. However, the maximal SNEG was obtained when the PV/T-SAC length was approximately 9 m under a large PV factor or a large DW thickness (Fig. 9a and c). It can be also observed that the profile of the SNEG was in a convex surface and the peak value of the SNEG was obtained when the air channel depths of the PV/T-SAC and the PCM TES unit were between the upper and lower bounds (Fig. 9m). Similar impacts due to the variation of the air channel depths of the PV/T-SAC and the PCM TES unit can also be observed in Fig. 9b, d, g, i, l, n, o, p, s and t. As the trends of the STC when simultaneously varying two key design parameters were relatively simple and most of them were monotonic, the results of the STC were therefore not provided.

The variations of the total exergy destruction when simultaneously varying two key design parameters are presented in Fig. 10. It can be observed that the variation trends of the exergy 
destruction were almost linear with the change of the PV/T-SAC length and the interactions between the PV/T-SAC length and other parameters were insignificant (Fig. 10a-f). The variation of the exergy destruction was mostly influenced by the PV/T-SAC length and higher exergy destruction was resulted when increasing the PV/T-SAC length. The exergy destruction always decreased with the increase of the PV factor (Fig. 10g-k) as the electricity was the pure exergy and its influence on the exergy destruction of the PV/T-SAC was much higher than that of the thermal energy generated from the PV/T-SAC. The total exergy destruction generally first decreased and then increased with the increase of the DW thickness (Fig. 10h, l, and p-r). The profile of the total exergy destruction was in a concave surface and the influence of the air channel depths of the PV/T-SAC and the PCM TES unit on the exergy destruction (Fig. 10m) was therefore opposite to those on the SNEG (Fig. 9m). Similar impacts on the total exergy destruction due to the variation of the air channel depths of the PV/T-SAC and the PCM TES unit can also be observed in Fig. 10g, i, l, n, o, p, s, and t.

The results from RSM analysis showed that the variation of the SNEG was non-linear and the parameters investigated are more or less interacted with each other. Therefore, such interactions should be considered in performance evaluation and optimal design of such systems.

The above results showed that PV/T-SAC represented the largest exergy destruction in the system, which is consistent with the results reported in the previous studies (Torio and Schmidt 2008; Torio et al. 2009). Therefore, it is necessary to use both energy analysis and exergy analysis to optimize the design of desiccant cooling systems driven by solar energy. In the meanwhile, it is also of great importance to improve the fan efficiency and optimize the sizes 
of air channels for PV/T-SAC and PCM TES units to enhance the overall efficiency.

\section{Conclusions}

This paper investigated the energy and exergy performance of a desiccant wheel cooling system integrated with a PCM TES and a PV/T-SAC for residential applications. A parametric study was first implemented to evaluate the influence of seven key design parameters (i.e. total length and air channel depth of the PV/T-SAC, PV factor, DW thickness, total amount of the PCM used, air channel depth of the PCM TES unit, and the PCM phase change temperature) on the system performance in terms of solar thermal contribution (STC), specific net electricity generation (SNEG), and the exergy destructions of individual components and the overall system. The interactions among these parameters were further investigated using the response surface method (RSM).

The results showed that the exergy destruction of the overall system was mainly contributed by the PV/T-SAC. The exergy destruction of the overall system, the SNEG and STC were increased with the increase of the PV/T-SAC length. The exergy performance and energy performance of the overall system were significantly influenced by the length and PV factor of the PV/T-SAC. The energy performance was substantially influenced by the DW thickness and total amount of the PCM used. Nonlinear interactions among the key design parameters were observed under the most test cases in terms of the SNEG of the system. The PV/T instead of the PV/T-SAC might be a better option to decrease exergy destruction. However, the result from the energy analysis showed that the PV/T-SAC using less PV/T could provide a higher STC while the SNEG can be maximized with a relatively high PV factor. The EH also contributed a larger part of the exergy destruction, which means that energy-efficient heating methods such 
as heat pumps might further improve the exergy performance of such systems.

\section{Nomenclature}

$$
\begin{aligned}
& \text { A }=\text { area, } \mathrm{m}^{2} \\
& A_{\text {fin }}=\text { fin surface area, } \mathrm{m}^{2} \\
& C_{p} \quad=\quad \text { specific heat capacity, } \mathrm{J} \mathrm{kg}^{-1} \mathrm{~K}^{-1} \\
& \dot{E} x_{\text {dest }}=\text { exergy destruction rate, } \mathrm{W} \\
& E x_{\text {solar }}=\text { exergy of solar radiation, } \mathrm{W} \\
& \dot{E} x_{\text {loss }}=\text { exergy loss rate, } \mathrm{W} \\
& \text { ex }=\text { specific exergy, } \mathrm{J} \mathrm{kg}^{-1} \\
& H_{\text {fin }}=\text { fin height, } \mathrm{m} \\
& h \quad=\quad \text { enthalpy, } \mathrm{J} \mathrm{kg}^{-1} \\
& h_{c}=\text { forced convection coefficient, } \mathrm{W} \mathrm{m} \mathrm{m}^{-2} \mathrm{~K}^{-1} \\
& I_{\text {solar }}=\text { solar radiation, } \mathrm{W} \mathrm{m}^{-2} \\
& k=\text { thermal conductivity, } \mathrm{W} \mathrm{m}^{-1} \mathrm{~K}^{-1} \\
& \dot{m}=\text { mass flow rate, } \mathrm{kg} \mathrm{s}^{-1} \\
& P \quad=\text { power, } \mathrm{W} \\
& p \quad=\text { pressure, } \mathrm{Pa} \\
& p_{0}=\text { pressure at the dead state, } \mathrm{Pa} \\
& \Delta p \quad=\text { pressure drop, } \mathrm{Pa} \\
& \text { Qheat = heating load, } \mathrm{W} \\
& \dot{Q}=\text { thermal energy transfer rate, } \mathrm{W}
\end{aligned}
$$




$$
\begin{array}{ll}
R & =\text { gas constant, } \mathrm{J} \mathrm{kg}^{-1} \mathrm{~K}^{-1} \\
R H_{0} & =\text { relative humidity at the dead state } \\
S & =\text { entropy, } \mathrm{J} \mathrm{K}^{-1} \mathrm{~kg}^{-1} \\
T & =\text { temperature, }{ }^{\circ} \mathrm{C} \text { or } \mathrm{K} \\
T_{0} & =\text { temperature at the dead state, }{ }^{\circ} \mathrm{C} \text { or } \mathrm{K} \\
V & =\text { volumetric air flow rate, } \mathrm{m}^{3} \mathrm{~s}^{-1} \\
W & =\text { humidity ratio, } \mathrm{kg} \mathrm{kg}^{-1} \\
W_{0} & =\text { humidity ratio at the dead state, } \mathrm{kg} \mathrm{kg}^{-1} \\
W_{d} & =\text { width, } \mathrm{m} \\
\rho & =\text { density, kg m}{ }^{-3} \\
\eta & =\text { efficiency } \\
v & =\text { specific volume, } \mathrm{m}^{3} \mathrm{~kg}^{-1} \\
\Delta x & =\text { length of each control volume }
\end{array}
$$

\section{Subscripts}

$$
\begin{aligned}
& a \quad=\text { air } \\
& \text { ap } \quad=\text { absorber plate } \\
& \text { ave } \quad=\text { average } \\
& \text { bp } \quad=\text { bottom plate } \\
& \text { chan }=\text { air channel } \\
& \text { char }=\text { charging } \\
& \text { DW }=\text { desiccant wheel }
\end{aligned}
$$




$$
\begin{aligned}
\text { EH } & =\text { electric heater } \\
\text { evap } & =\text { evaporation } \\
\text { IEC } & =\text { indirect evaporative cooler } \\
\text { in } & =\text { inlet } \\
\text { out } & =\text { outlet } \\
\text { pri } & =\text { primary } \\
\text { pro } & =\text { process } \\
\text { PS } & =\text { PV/T-SAC } \\
\text { pv } & =\text { PV panel } \\
\text { reg } & =\text { regeneration } \\
\text { sat } & =\text { saturation } \\
\text { sec } & =\text { secondary } \\
\text { sup } & =\text { supply } \\
\text { v } & =\text { wapor } \\
\text { s } &
\end{aligned}
$$

\section{Abbreviations}

DW desiccant wheel

DWC desiccant wheel cooling

EH electric heater

HRU heat recovery unit

IEC indirect evaporative cooler

IWEC international weather for energy calculation 
PCM phase change material

PV photovoltaic

PV/T photovoltaic/thermal

SAC solar air collector

SD solar decathlon

SNEG specific net electricity generation

STC solar thermal contribution

TES thermal energy storage

\section{References}

Abbassi, Y., E. Baniasadi, and H. Ahmadikia. 2017. Comparative performance analysis of different solar desiccant dehumidification systems. Energy and Buildings 150:37-51. Bejan, A. 2016. Advanced engineering thermodynamics. Chichester: John Wiley \& Sons.

Caliskan, H., D.Y. Lee, and H. Hong. 2019. Enhanced thermodynamic assessments of the novel desiccant air cooling system for sustainable energy future. Journal of Cleaner Production 211:213-221.

Chaudhary, G.Q., M. Ali, N.A. Sheikh, and S. Khushnood. 2018. Integration of solar assisted solid desiccant cooling system with efficient evaporative cooling technique for separate load handling. Applied Thermal Engineering 140:696-706.

Chen, Y., H. Yang, and Y. Luo. 2016. Indirect evaporative cooler considering condensation from primary air: model development and parameter analysis. Building and Environment 95:330-345. 
Chen, Y., H. Yang, and Y. Luo. 2017. Parameter sensitivity analysis and configuration optimization of indirect evaporative cooler (IEC) considering condensation. Applied Energy 194:440-453.

Chen, Y., H. Yang, and Y. Luo. 2018. Investigation on solar assisted liquid desiccant dehumidifier and evaporative cooling system for fresh air treatment. Energy 143:114-127.

Chow, T.T., G. Pei, K.F. Fong, Z. Lin, A.L.S. Chan, and J. Ji. 2009. Energy and exergy analysis of photovoltaic-thermal collector with and without glass cover. Applied Energy 86(3):310-316.

De Antonellis, S., C.M. Joppolo, and L. Molinaroli. 2010. Simulation, performance analysis and optimization of desiccant wheels. Energy and Buildings 42(9):1386-1393.

Dincer, I. and M. Rosen. 2002. Thermal energy storage: systems and applications. Chichester: John Wiley \& Sons.

Dolado, P., A. Lazaro, J.M. Marin, and B. Zalba. 2011. Characterization of melting and solidification in a real scale PCM-air heat exchanger: Numerical model and experimental validation. Energy Conversion and Management 52(4):1890-1907.

Enteria, N., H. Yoshino, R. Takaki, H. Yonekura, A. Satake, and A. Mochida. 2013. First and second law analyses of the developed solar-desiccant air-conditioning system (SDACS) operation during the summer day. Energy and Buildings 60:239-251.

Fan, W., G. Kokogiannakis, and Z. Ma. 2018. A multi-objective design optimisation strategy for hybrid photovoltaic thermal collector (PVT)-solar air heater (SAH) systems with fins. Solar Energy 163:315-328.

Fan, W., G. Kokogiannakis, Z. Ma, and P. Cooper. 2017. Development of a dynamic model 
for a hybrid photovoltaic thermal collector-Solar air heater with fins. Renewable Energy 101:816-834.

Firozjaei, M.R., M. Bazargan, and M. Amidpour. 2015. Evaluation of a low-cost solar cooling system for hot and humid regions in Iran. Science and Technology for the Built Environment 21(4):438-447.

Fong, K.F., and C.K. Lee. 2018. New perspectives in solid desiccant cooling for hot and humid regions. Energy and Buildings 158:1152-1160.

Gunerhan, H., and A. Hepbasli. 2007. Exergetic modeling and performance evaluation of solar water heating systems for building applications. Energy and Buildings 39(5):509516.

Hürdoğan, E., O. Buyükalaca, A. Hepbasli, and T. Y1lmaz. 2011. Exergetic modeling and experimental performance assessment of a novel desiccant cooling system. Energy and Buildings 43(6):1489-1498.

Jegadheeswaran, S., S.D. Pohekar, and T. Kousksou. 2010. Exergy based performance evaluation of latent heat thermal storage system: a review. Renewable and Sustainable Energy Reviews 14(9):2580-2595.

Kang, H., G. Lee, and D.Y. Lee. 2015. Explicit analytic solution for heat and mass transfer in a desiccant wheel using a simplified model. Energy 93:2559-2567.

Klein, S.A., W.A. Beckman, J.W. Mitchell, J.A. Duffie, N.A. Duffie, T.L. Freeman, and J.C. Mitchell. 2010. TRNSYS 17: A Transient System Simulation Program. Solar Energy Laboratory. University of Wisconsin. Madison, USA.

Lin, J., D.T. Bui, R. Wang, and K.J. Chua. 2018. On the exergy analysis of the counter-flow 
dew point evaporative cooler. Energy 165:958-971.

Lin, W., Z. Ma, H. Ren, S. Gschwander, and S. Wang. 2019. Multi-objective optimisation of thermal energy storage using phase change materials for solar air systems. Renewable Energy 130:1116-1129.

Lin, W., Z. Ma, P. Cooper, M.I. Sohel, and L. Yang. 2016. Thermal performance investigation and optimization of buildings with integrated phase change materials and solar photovoltaic thermal collectors. Energy and Buildings 116:562-573.

Lu, J., T. Long, R. Hu, Y. Li, and Z. Qiao. 2019. Effects of various parameters on thermal performance of a SWHS-LHS system: A numerical study. Science and Technology for the Built Environment 25(5):563-569.

Ma, Z., W. Lin, and M.I. Sohel. 2016. Nano-enhanced phase change materials for improved building performance. Renewable and Sustainable Energy Reviews 58:1256-1268.

Masy, G., E. Georges, C. Verhelst, V. Lemort, and P. André. 2015. Smart grid energy flexible buildings through the use of heat pumps and building thermal mass as energy storage in the Belgian context. Science and Technology for the Built Environment 21:800-811.

Mazo, J., A.T. El Badry, J. Carreras, M. Delgado, D. Boer, and B. Zalba. 2015. Uncertainty propagation and sensitivity analysis of thermo-physical properties of phase change materials (PCM) in the energy demand calculations of a test cell with passive latent thermal storage. Applied Thermal Engineering 90:596-608.

Montgomery, D.C. 2012. The text book of design and analysis of experiments. Chichester: John Wiley \& Sons.

Nciri, R., C. Ali, and H.B. Bacha. 2013. Design and analysis of an original multi-bed 
dehumidifier used for air-conditioning prototype powered by solar energy. $H V A C \& R$ Research 19(6):732-743.

Papachristou, A.C., C.A. Vallianos, V. Dermardiros, A.K. Athienitis, and J.A. Candanedo. 2018. A numerical and experimental study of a simple model-based predictive control strategy in a perimeter zone with phase change material. Science and Technology for the Built Environment 24(9):933-944.

Petela, R. 2003. Exergy of undiluted thermal radiation. Solar Energy 74(6):469-488.

Ren, H., Z. Ma, W. Lin, S. Wang, and W. Li. 2019. Optimal design and size of a desiccant cooling system with onsite energy generation and thermal storage using a multilayer perceptron neural network and a genetic algorithm. Energy Conversion and Management 180:598-608.

Ren, H., Z. Ma, W. Lin, W. Fan, and W. Li. 2018. Integrating photovoltaic thermal collectors and thermal energy storage systems using phase change materials with rotary desiccant cooling systems. Sustainable Cities and Society 36:131-143.

Riangvilaikul, B. and S. Kumar. 2010. An experimental study of a novel dew point evaporative cooling system. Energy and Buildings 42(5):637-644.

Rubitherm. 2018. https://www.rubitherm.eu/, accessed 10 September 2018.

Sheng, Y., Y. Zhang, Y. Sun, and G. Ding. 2015. Thermodynamic analysis of desiccant wheel coupled to high-temperature heat pump system. Science and Technology for the Built Environment 21(8):1165-1174.

Speerforck, A., J. Ling, V. Aute, R. Radermacher, and G. Schmitz. 2017. Modeling and simulation of a desiccant assisted solar and geothermal air conditioning system. Energy 
141:2321-2336.

Subiantoro, A. 2019. Feasibility analysis of the hybrid dehumidifier-air conditioner technology for small-scale household applications in the tropics. Science and Technology for the Built Environment 25(2):177-188.

Torio, H., A. Angelotti, and D. Schmidt. 2009. Exergy analysis of renewable energy-based climatisation systems for buildings: A critical view. Energy and Buildings 41(3):248-271.

Torio, H., and D. Schmidt. 2008. Exergetic assessment and contribution of solar energy systems to the energy performance of buildings. Proceedings of the Nordic Symposium of Building Physics, Copenhagen, Denmark.

Tu, R., X.H. Liu, and Y. Jiang. 2015. Lowering the regeneration temperature of a rotary wheel dehumidification system using exergy analysis. Energy Conversion and Management 89:162-174.

Tu, Y., and R. Wang. 2017. Theoretical investigation of a novel unitary solid desiccant air conditioner. Science and Technology for the Built Environment 23(1):151-156.

Wang, Z., F. Wang, J. Liu, Z. Ma, E. Han, and M. Song. 2017. Field test and numerical investigation on the heat transfer characteristics and optimal design of the heat exchangers of a deep borehole ground source heat pump system. Energy Conversion and Management 153:603-615.

Wu, X.N., T.S. Ge, Y.J. Dai, and R.Z. Wang. 2018. Review on substrate of solid desiccant dehumidification system. Renewable and Sustainable Energy Reviews 82:3236-3249.

Yamaguchi, S., and K. Saito. 2013. Numerical and experimental performance analysis of rotary desiccant wheels. International Journal of Heat and Mass Transfer 60:51-60. 
Zeinelabdein, R., S. Omer, and G. Gan. 2018. Critical review of latent heat storage systems for free cooling in buildings. Renewable and Sustainable Energy Reviews 82:2843-2868.

Zhang, T., X. Liu, and J. Liu. 2017. Performance investigation and exergy analysis of airhandling processes using liquid desiccant and a desiccant wheel. Science and Technology for the Built Environment 23(1):105-115.

Zhao, Y., Y. You, H.B. Liu, C.Y. Zhao, and Z.G. Xu. 2018. Experimental study on the thermodynamic performance of cascaded latent heat storage in the heat charging process. Energy 157:690-706.

\section{Appendix}

The response surface models developed for predicting the SNEG, STC, and total exergy destruction are presented in Eqs. (A1), (A2), and (A3), respectively.

$$
\begin{aligned}
& S N E G=a_{0}+a_{1} A+a_{2} B+a_{3} C+a_{4} D+a_{5} E+a_{6} F+a_{7} G+b_{12} A B+b_{13} A C+b_{14} A D+ \\
& b_{15} A E+b_{16} A F+b_{17} A G+b_{24} B D+b_{25} B E+b_{26} B F+b_{34} C D+b_{45} D E+b_{46} D F+ \\
& b_{56} E F+b_{57} E G+b_{67} F G+c_{1} A^{2}+c_{3} C^{2}+c_{4} D^{2}+c_{5} E^{2} \\
& S T C=a_{0}+a_{1} A+a_{2} B+a_{3} C+a_{4} D+a_{5} E+a_{6} F+a_{7} G+b_{12} A B+b_{13} A C+b_{14} A D+ \\
& b_{15} A E+b_{16} A F+b_{17} A G+b_{24} B D+b_{34} C D+b_{35} C E+b_{36} C F+b_{37} C G+b_{45} D E+ \\
& b_{46} D F+b_{56} E F+b_{57} E G+b_{67} F G+c_{1} A^{2}+c_{4} D^{2}+c_{7} G^{2} \\
& E x_{d e s t, t o t a l}=a_{0}+a_{1} A+a_{2} B+a_{3} C+a_{4} D+a_{5} E+a_{6} F+a_{7} G+b_{12} A B+b_{13} A C+ \\
& b_{14} A D+b_{15} A E+b_{16} A F+b_{17} A G+b_{24} B D+b_{34} C D+b_{45} D E+b_{46} D F+b_{56} E F+ \\
& b_{57} E G+b_{67} F G+c_{1} A^{2}+c_{3} C^{2}+c_{4} D^{2}+c_{5} E^{2}
\end{aligned}
$$

where $A$ is the PV/T-SAC length, $B$ is the PV factor, $C$ is the PV/T-SAC air channel depth, $D$ is 
the DW thickness, $E$ is the PCM TES unit air channel depth, $F$ is the number of PCM layers, and $G$ is the PCM phase change temperature. The coefficients used are summarized in Table A1.

Table A1. Coefficients of Eqs. (A1), (A2), and (A3).

\begin{tabular}{lllllll}
\hline SNEG & & & & & & \\
\hline$a_{0}$ & $a_{1}$ & $a_{2}$ & $a_{3}$ & $a_{4}$ & $a_{5}$ & $a_{6}$ \\
-613.4239 & 89.2097 & 337.1042 & 590.7365 & 1074.691 & 5742.023 & 11.9412 \\
$a_{7}$ & $b_{12}$ & $b_{13}$ & $b_{14}$ & $b_{15}$ & $b_{16}$ & $b_{17}$ \\
-3.2223 & -19.6057 & 231.2372 & -41.6715 & 134.4848 & -0.6563 & 0.3061 \\
$b_{24}$ & $b_{25}$ & $b_{26}$ & $b_{34}$ & $b_{45}$ & $b_{46}$ & $b_{56}$ \\
-123.2651 & -748.9322 & -4.7448 & 2124.2878 & 2461.4914 & -4.4336 & -104.1454 \\
$b_{57}$ & $b_{67}$ & $c_{1}$ & $c_{3}$ & $c_{4}$ & $c_{5}$ & \\
-30.7382 & 0.03417 & -4.1034 & -84761.47 & -899.7272 & $-1.40559 \mathrm{E} 5$ & \\
\hline STC & & & & & & \\
\hline$a_{0}$ & $a_{1}$ & $a_{2}$ & $a_{3}$ & $a_{4}$ & $a_{5}$ & $a_{6}$ \\
0.3767 & 0.0747 & -0.1703 & -4.0415 & 1.2890 & 5.5989 & $3.4652 \mathrm{E}-3$ \\
$a_{7}$ & $b_{12}$ & $b_{13}$ & $b_{14}$ & $b_{15}$ & $b_{16}$ & $b_{17}$ \\
$4.3129 \mathrm{E}-3$ & 0.0107 & 0.3687 & -0.0522 & 0.4539 & $-6.8520 \mathrm{E}-4$ & $6.4287 \mathrm{E}-4$ \\
$b_{24}$ & $b_{34}$ & $b_{35}$ & $b_{36}$ & $b_{37}$ & $b_{45}$ & $b_{46}$ \\
0.1289 & 3.3102 & -19.3049 & 0.0325 & -0.0232 & 4.2673 & $-6.6538 \mathrm{E}-3$ \\
$b_{56}$ & $b_{57}$ & $b_{67}$ & $c_{1}$ & $c_{4}$ & $c_{7}$ & \\
0.1303 & -0.0474 & $9.0527 \mathrm{E}-5$ & $-5.5176 \mathrm{E}-3$ & -1.2068 & $-8.5186 \mathrm{E}-5$ & \\
\hline$E x_{\text {dest,total }}$ & & & & & & \\
\hline$a_{0}$ & $a_{1}$ & $a_{2}$ & $a_{3}$ & $a_{4}$ & $a_{5}$ & $a_{6}$ \\
8658.427 & 5340.804 & 381.8026 & -44576.97 & -13819.54 & $-1.2976 \mathrm{E} 5$ & -130.8634 \\
$a_{7}$ & $b_{12}$ & $b_{13}$ & $b_{14}$ & $b_{15}$ & $b_{16}$ & $b_{17}$ \\
38.7120 & -399.3880 & -3159.1339 & 448.4571 & -3703.446 & 5.3532 & -3.5388 \\
$b_{24}$ & $b_{34}$ & $b_{45}$ & $b_{46}$ & $b_{56}$ & $b_{57}$ & $b_{67}$ \\
-29734.76 & -1293.179 & -39993.69 & 86.7528 & 2893.393 & 444.9587 & -0.4774 \\
$c_{1}$ & $c_{3}$ & $c_{4}$ & $c_{5}$ & & & \\
48.9032 & $2.0583 \mathrm{E} 6$ & 1479.3622 & $3.4256 \mathrm{E} 6$ & & & \\
\hline & & & & & & \\
\hline
\end{tabular}


Table 1. Operation modes of the DWC-TES-PV/T-SAC system.

\begin{tabular}{lll}
\hline & Cooling & Heating \\
\hline Mode I & PV/T-SAC for DW regeneration and & PV/T-SAC for space heating and \\
& PCM charging & PCM charging \\
Mode II & PV/T-SAC for PCM charging only & PV/T-SAC for PCM charging only \\
Mode III & PCM discharging for DW regeneration & PCM discharging for space heating \\
\hline
\end{tabular}

Table 2. Main parameters used in the baseline design and their variation ranges.

\begin{tabular}{lcl|lll}
\hline Parameter & Baseline & $\begin{array}{l}\text { Variation } \\
\text { range }\end{array}$ & Parameter & $\begin{array}{l}\text { Baseline } \\
\text { Variation } \\
\text { range }\end{array}$ \\
\hline $\begin{array}{l}\text { PV/T-SAC length } \\
(\mathrm{m})\end{array}$ & 8.0 & {$[6.0,10.0]$} & $\begin{array}{l}\text { PCM TES unit air } \\
\text { channel depth }(\mathrm{mm})\end{array}$ & 10 & {$[3,20]$} \\
PV factor & 0.6 & {$[0.5,0.8]$} & $\begin{array}{l}\text { Number of PCM } \\
\text { layers } \\
\text { PCM phase change } \\
\text { temperature }\left({ }^{\circ} \mathrm{C}\right)\end{array}$ & 65 & $\{10,11, \ldots$, \\
$\begin{array}{l}\text { PV/T-SAC air } \\
\text { channel depth } \\
\text { (mm) }\end{array}$ & 25 & {$[10,30]$} & {$[55,75]$} \\
DW thickness (m) & 0.3 & {$[0.2,0.4]$} & & & \\
\hline
\end{tabular}

Table 3. Specifications of the DWC-TES-PV/T-TES system.

\begin{tabular}{|c|c|c|c|}
\hline Parameter & Value & Parameter & Value \\
\hline PV/T-SAC width (m) & 4.0 & IEC length (m) & 1.0 \\
\hline PV/T-SAC slope $\left(^{\circ}\right)$ & 18.4 & IEC extra ratio & 0.3 \\
\hline $\begin{array}{l}\text { PV/T-SAC rated flow rate during } \\
\text { cooling seasons }\left(\mathrm{kg} \mathrm{h}^{-1}\right)\end{array}$ & 900 & Thermal efficiency of HRU & 0.75 \\
\hline $\begin{array}{l}\text { PV/T-SAC rated flow rate during } \\
\text { heating seasons }\left(\mathrm{kg} \mathrm{h}^{-1}\right)\end{array}$ & 1200 & Electrical efficiency of fan & 0.65 \\
\hline DW diameter (m) & 0.4 & PCM TES unit width (m) & 1.2 \\
\hline DW rotation speed (rph) & $10-24$ & PCM brick thickness (m) & 0.02 \\
\hline $\begin{array}{l}\text { Regeneration to process side area } \\
\text { ratio }\end{array}$ & $1: 1$ & $\begin{array}{l}\text { PCM thermal conductivity ( } \mathrm{W} \mathrm{m}^{-1} \\
\left.\mathrm{~K}^{-1}\right)\end{array}$ & 0.2 \\
\hline $\begin{array}{l}\text { Regeneration to process side flow } \\
\text { rate ratio }\end{array}$ & $1: 1$ & PCM heat storage capacity $\left(\mathrm{kJ} \mathrm{kg}^{-1}\right)$ & 250 \\
\hline IEC width (m) & 0.4 & PCM TES unit length (m) & 3.0 \\
\hline
\end{tabular}




\section{List of figure captions}

Fig. 1. Schematic of the DWC system integrated with PV/T-SAC and PCM TES unit.

Fig. 2. Simulation system of the DWC-TES-PV/T-SAC system developed using TRNSYS.

Fig. 3. Validation of the DW model and IEC model.

Fig. 4. Cooling and heating load of the SD house based on IWEC weather data of Brisbane.

Fig. 5. Variations in exergy destructions of DW, HRU, IEC, TES unit, EH, and fan when varying the design parameters.

Fig. 6. Variations in the total exergy destruction and the exergy destruction of the PV/T-SAC when varying the PV/T-SAC length, PV factor, PV/T-SAC air channel depth, and DW thickness. Fig. 7. Influence of the design parameters on the SNEG and STC.

Fig. 8. Influence of the design parameters on the power consumptions of the EH and fan.

Fig. 9. Variations of SNEG with the change of seven key design parameters (A - PV/T-SAC length; B - PV factor; C - PV/T-SAC air channel depth; D - DW thickness; E - PCM TES unit air channel depth; F - number of PCM layers; and G - PCM phase change temperature).

Fig. 10. Variations of total exergy destruction with the change of seven key design parameters (A - PV/T-SAC length; B - PV factor; C - PV/T-SAC air channel depth; D - DW thickness; E PCM TES unit air channel depth; F - number of PCM layers; and G - PCM phase change temperature). 


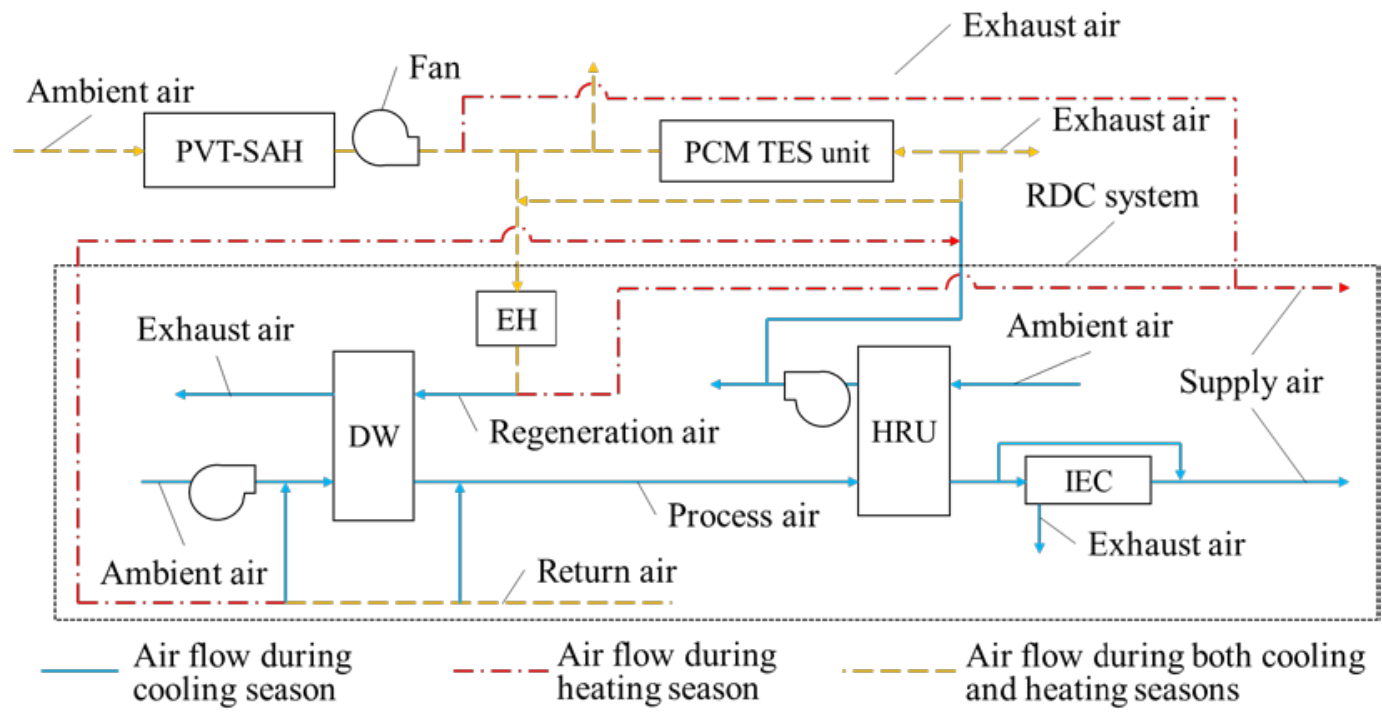

Fig. 1. Schematic of the DWC system integrated with PV/T-SAC and PCM TES unit.

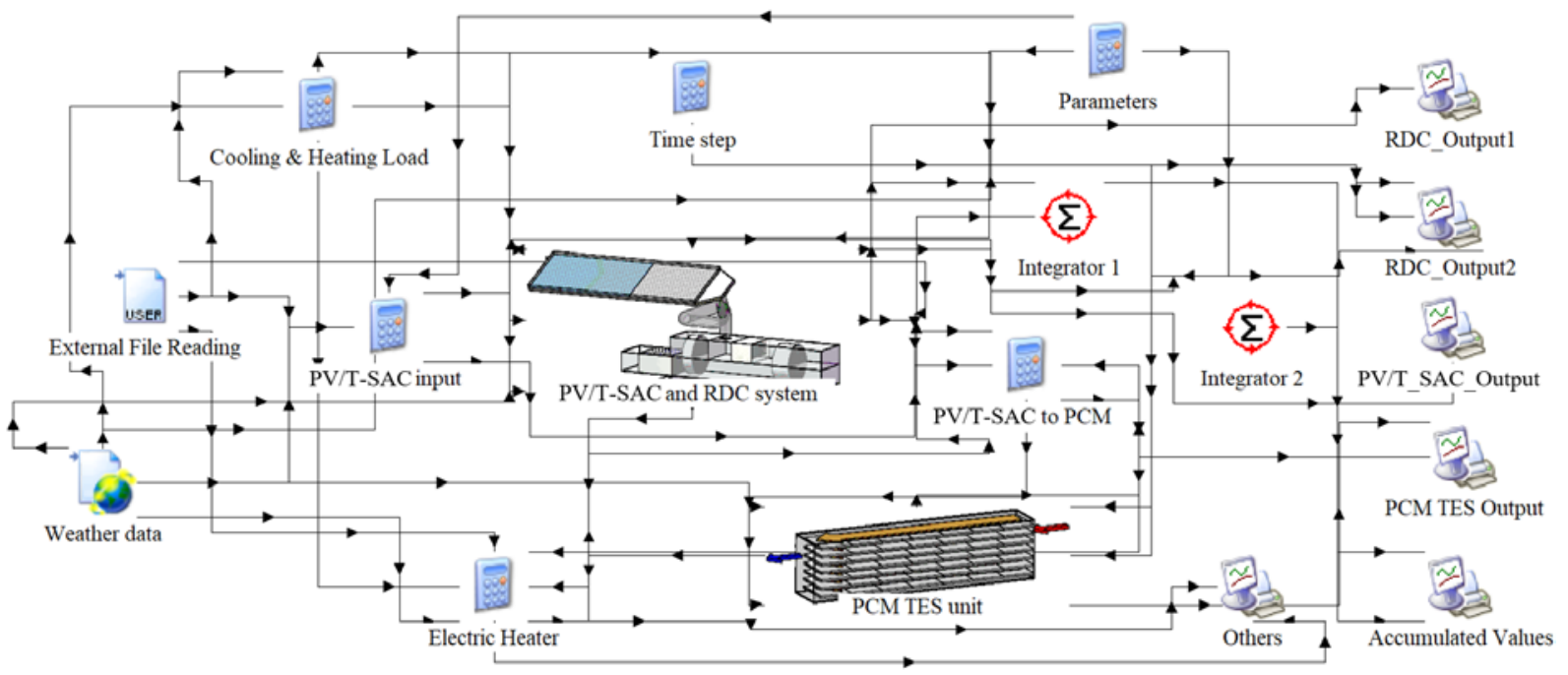

Fig. 2. Simulation system of the DWC-TES-PV/T-SAC system developed using TRNSYS. 


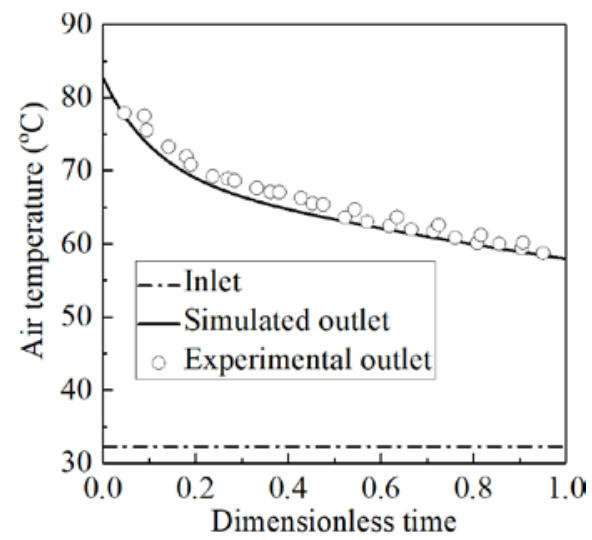

a) Outlet air temperature (DW)

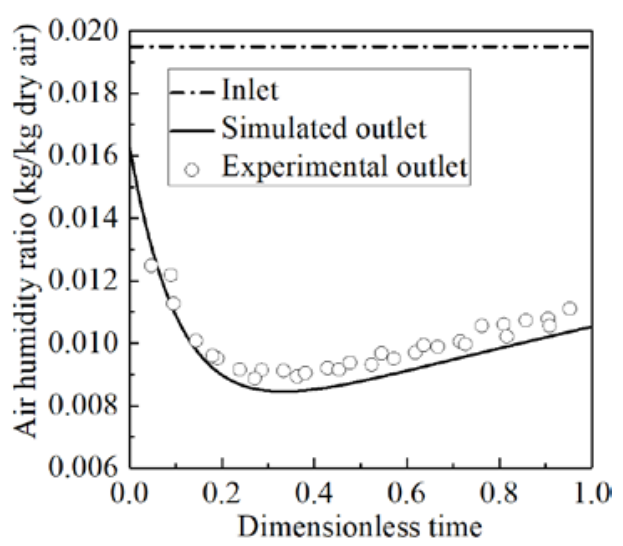

b) Outlet air humidity ratio (DW)

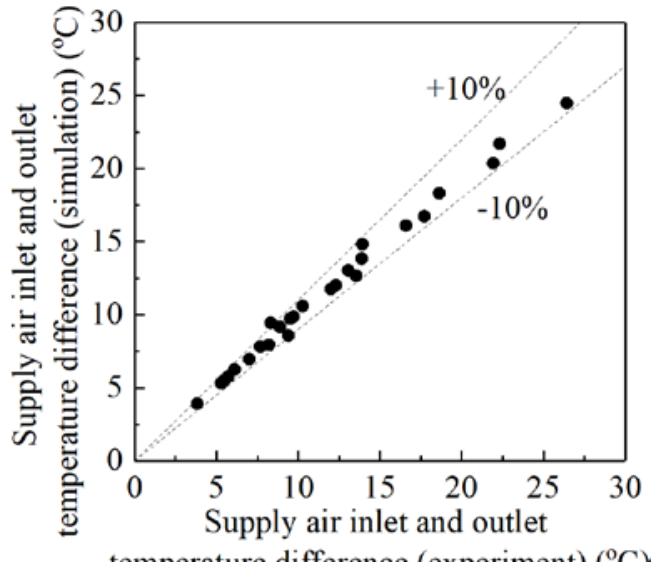

c) Temperature difference (IEC)

Fig. 3. Validation of the DW model and IEC model. 


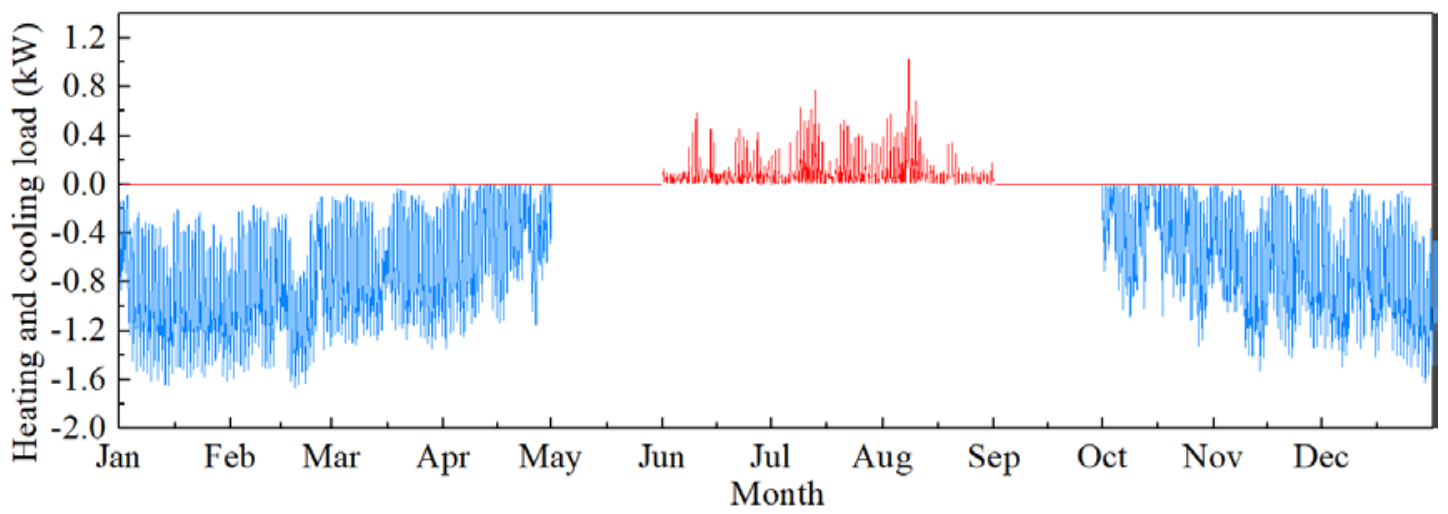

Fig. 4. Cooling and heating load of the SD house based on IWEC weather data of Brisbane.

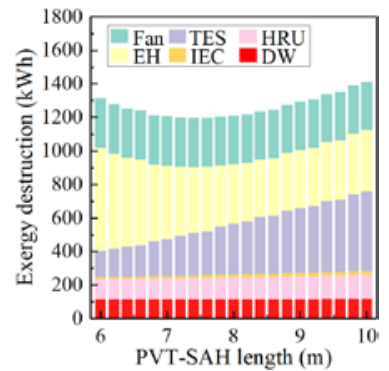

a) PV/T-SAC length
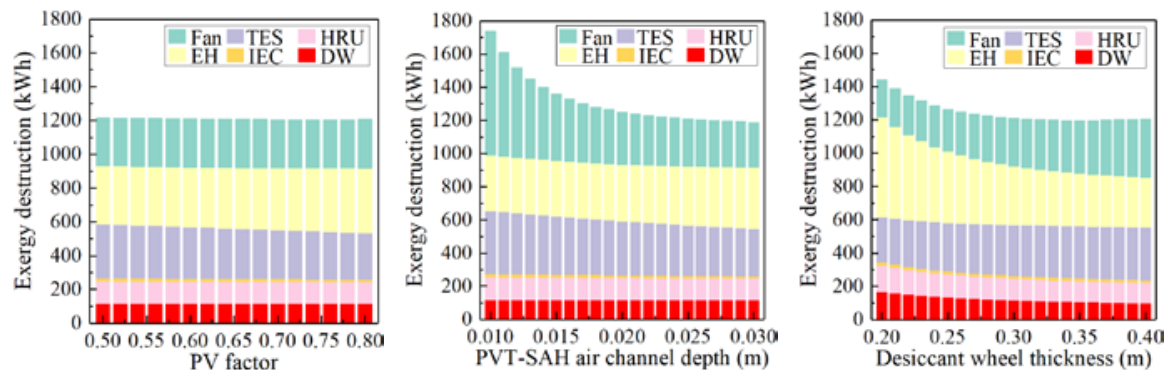

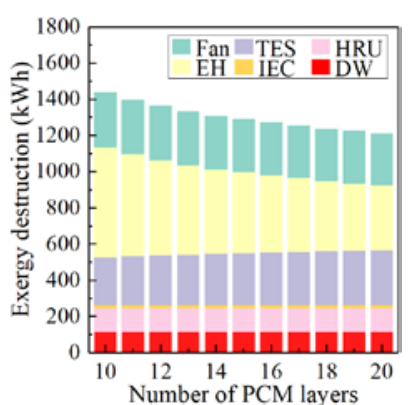

e) PCM layers b) PV factor
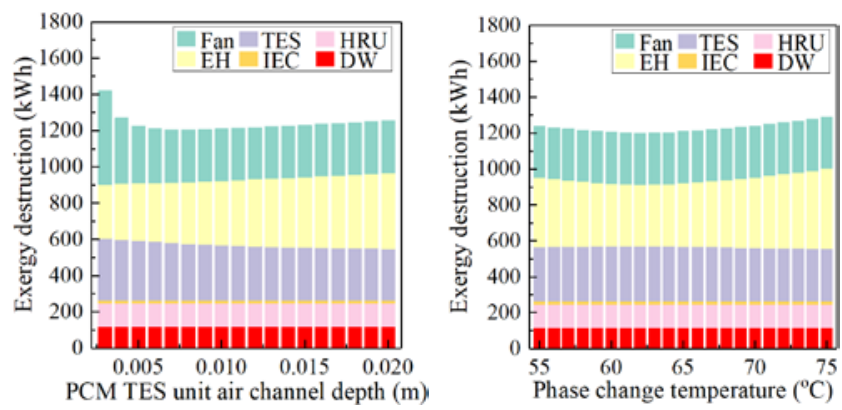

f) PCM air channel depth

c) PV/T-SAC air channel depth d) DW thickness

Fig. 5. Variations in exergy destructions of DW, HRU, IEC, TES unit, EH, and fan when varying the design parameters. 


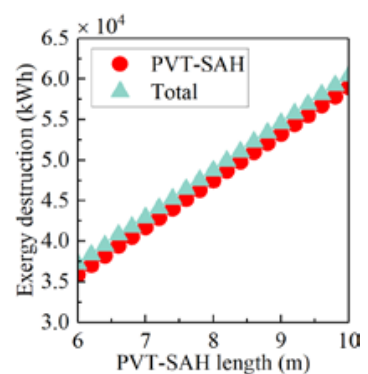

a) PV/T-SAC length
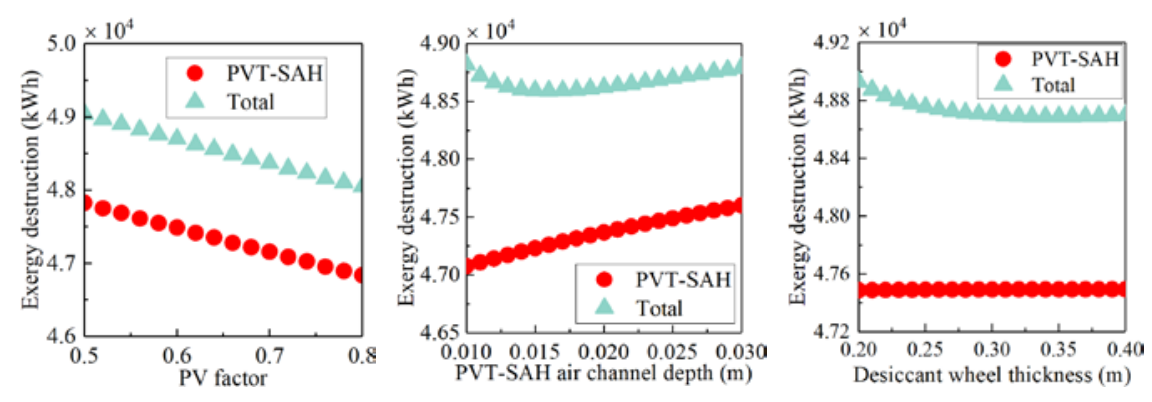

b) PV factor

c) PV/T-SAC air channel depth

d) DW thickness

Fig. 6. Variations in the total exergy destruction and the exergy destruction of the PV/T-SAC when varying the PV/T-SAC length, PV factor, PV/T-SAC air channel depth, and DW thickness.
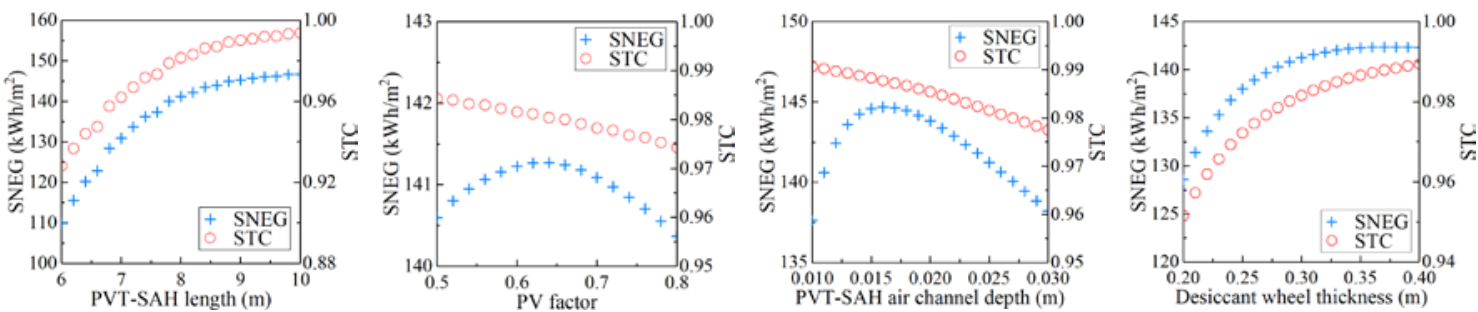

a) PV/T-SAC length

b) PV factor

c) PV/T-SAC air channel depth

d) DW thickness

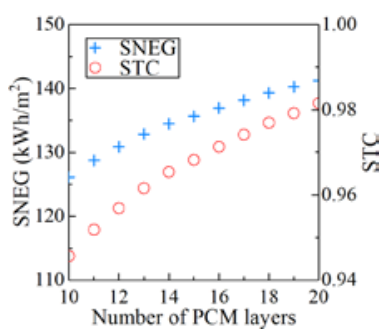

e) PCM layers

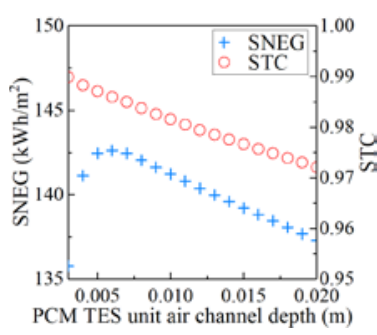

f) PCM air channel depth

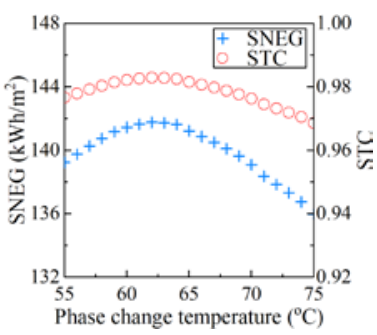

g) Phase change temperature

Fig. 7. Influence of the design parameters on the SNEG and STC. 


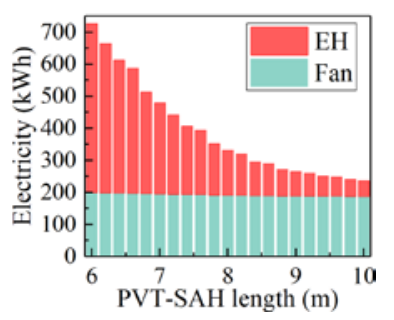

a) PV/T-SAC length
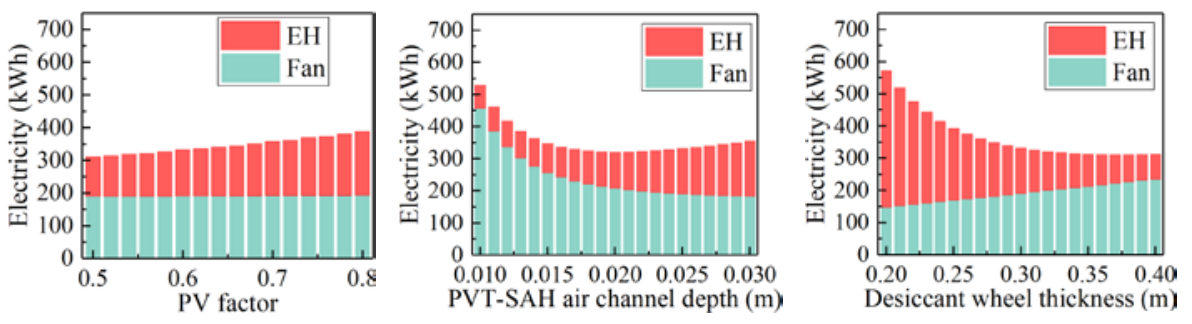

b) PV factor

c) PV/T-SAC air channel depth

d) DW thickness
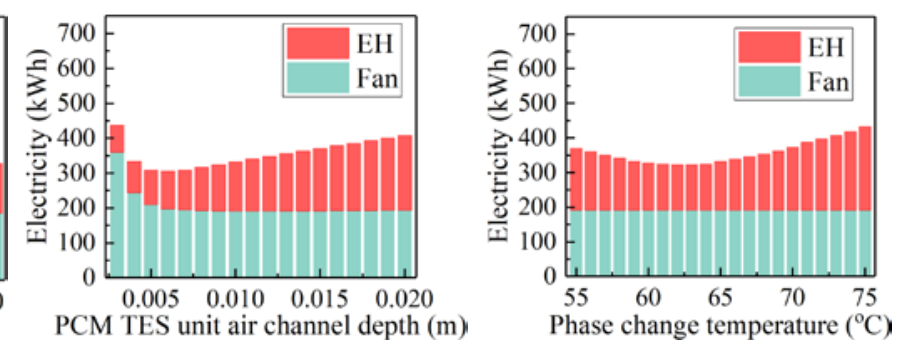
e) PCM layers
f) PCM air channel depth
g) PCM phase change temperature

Fig. 8. Influence of the design parameters on the power consumptions of the EH and fan.

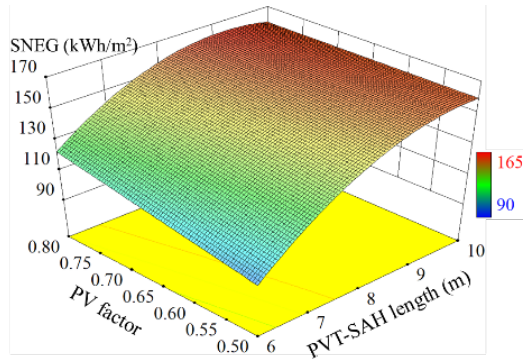

a) $A \times B$

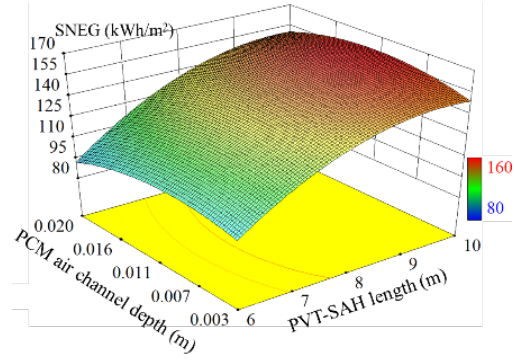

d) $\mathrm{A} \times \mathrm{E}$

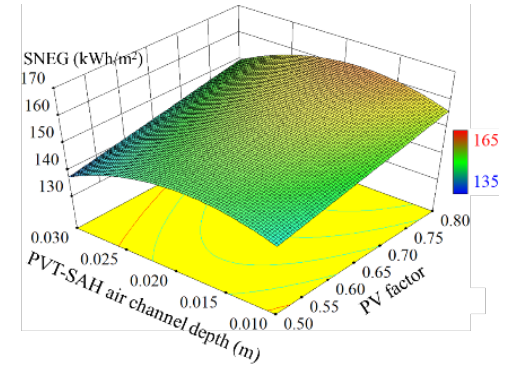

g) $\mathrm{B} \times \mathrm{C}$

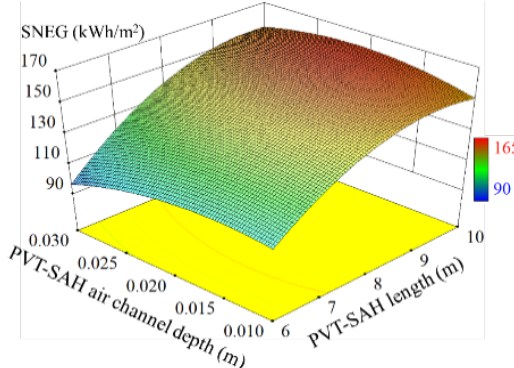

b) $\mathrm{A} \times \mathrm{C}$

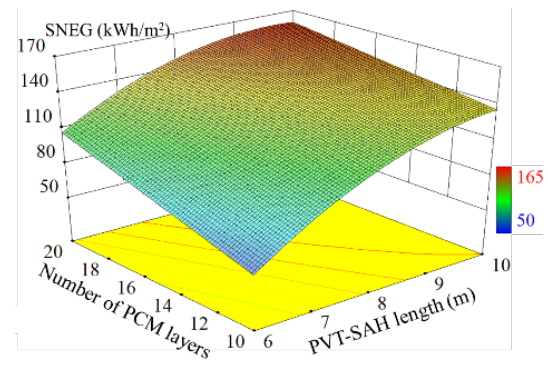

e) $\mathrm{A} \times \mathrm{F}$

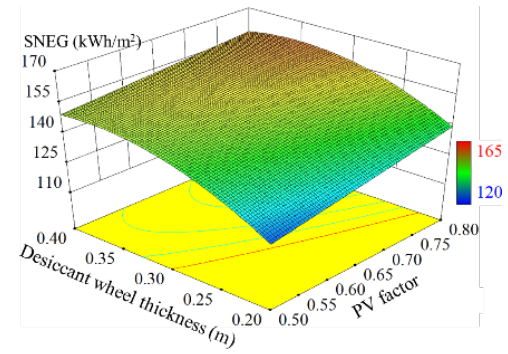

h) $B \times D$

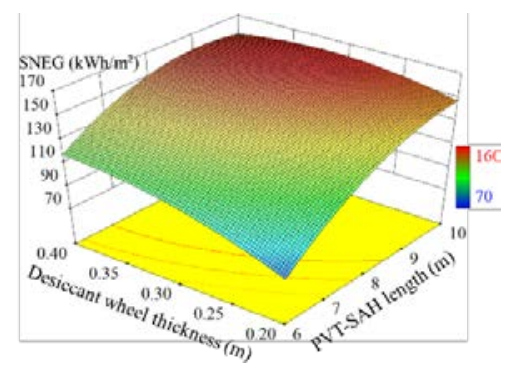

c) $\mathrm{A} \times \mathrm{D}$

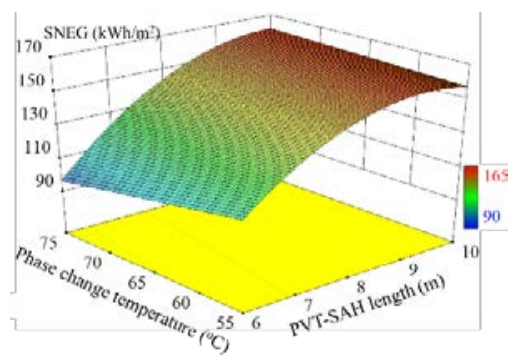

f) $A \times G$

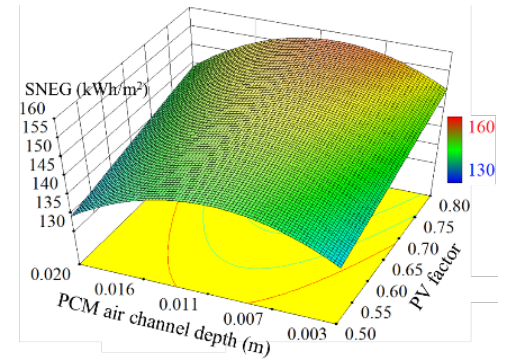

i) $\mathrm{B} \times \mathrm{E}$ 


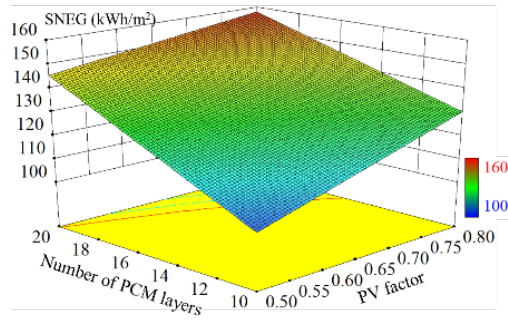

j) $B \times F$

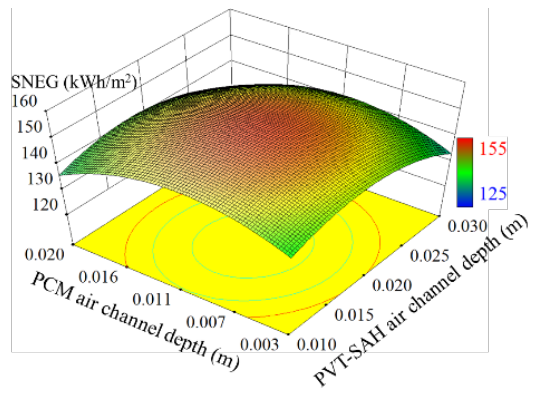

m) $\mathrm{C} \times \mathrm{E}$

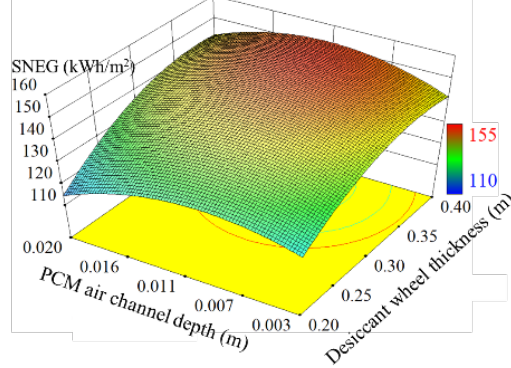

p) $\mathrm{D} \times \mathrm{E}$

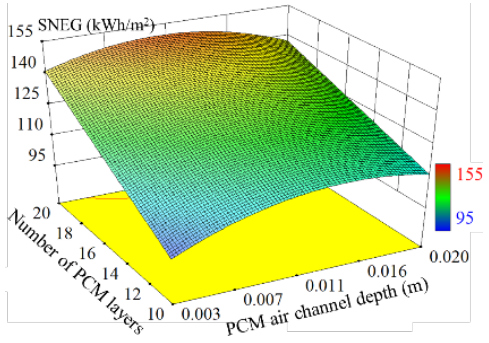

s) $\mathrm{E} \times \mathrm{F}$

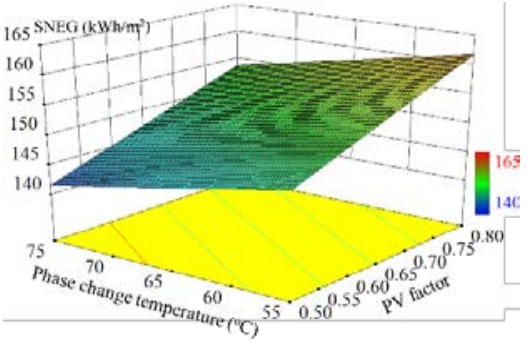

k) $B \times G$

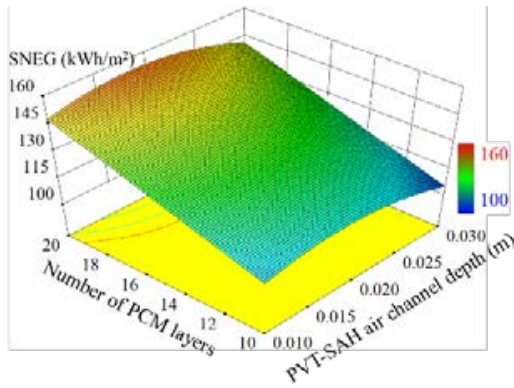

n) $\mathrm{C} \times \mathrm{F}$

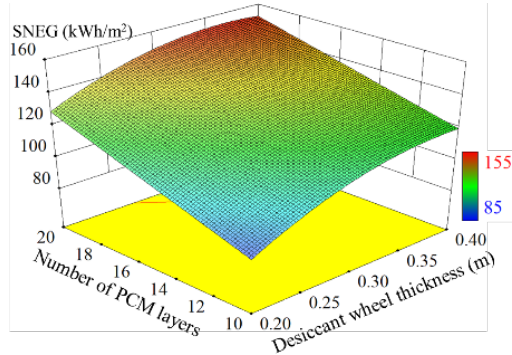

q) $\mathrm{D} \times \mathrm{F}$

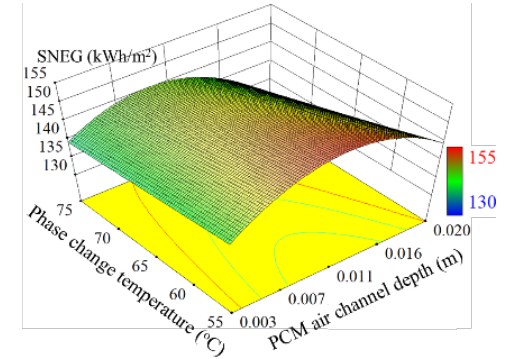

t) $E \times G$

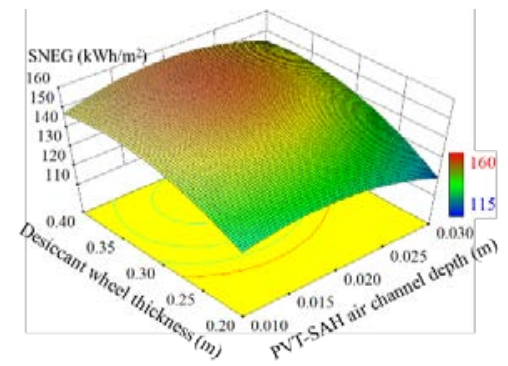

l) $C \times D$

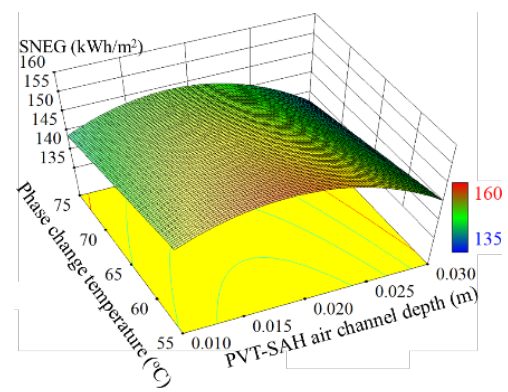

o) $\mathrm{C} \times \mathrm{G}$

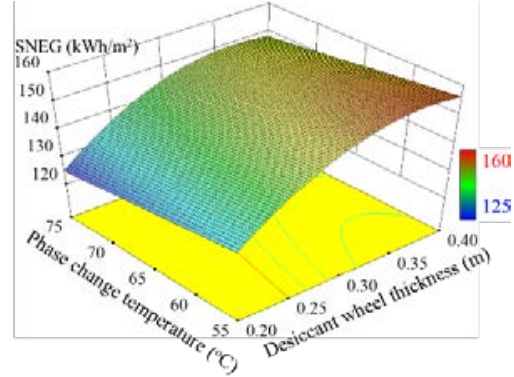

r) $\mathrm{D} \times \mathrm{G}$

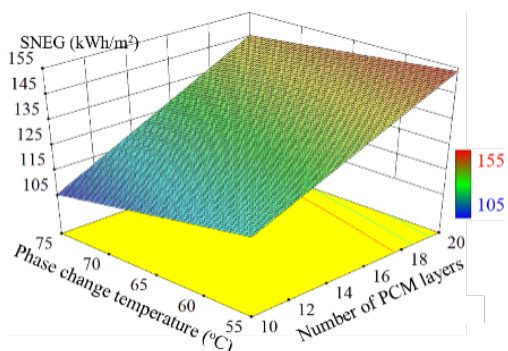

u) $F \times G$

Fig. 9. Variations of SNEG with the change of seven key design parameters (A - PV/T-SAC length; B - PV factor; C - PV/T-SAC air channel depth; D - DW thickness; E - PCM TES unit air channel depth; F - number of PCM layers; and G - PCM phase change temperature). 


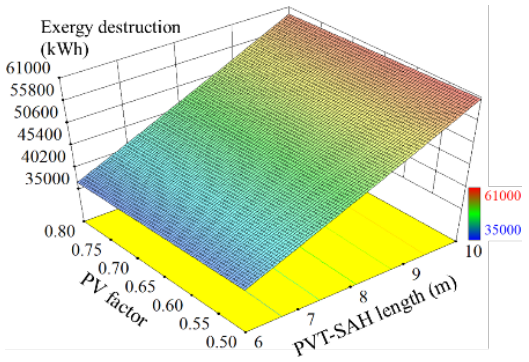

a) $A \times B$

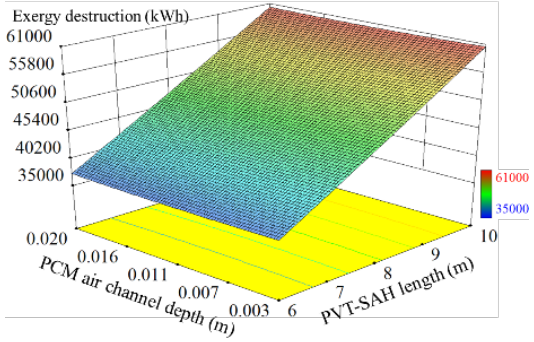

d) $\mathrm{A} \times \mathrm{E}$

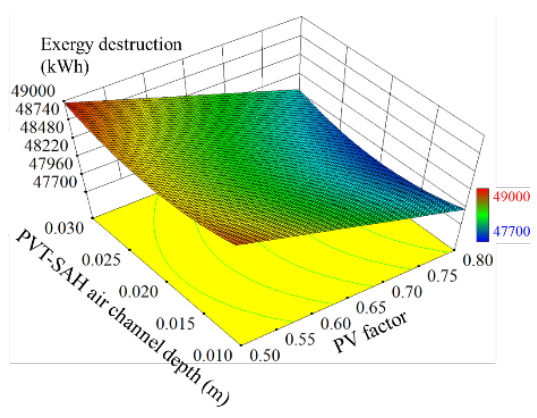

g) $\mathrm{B} \times \mathrm{C}$

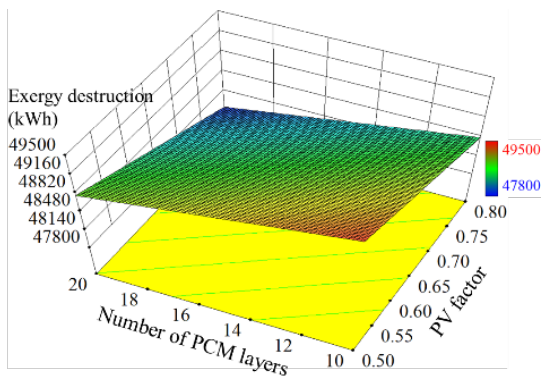

j) $B \times F$

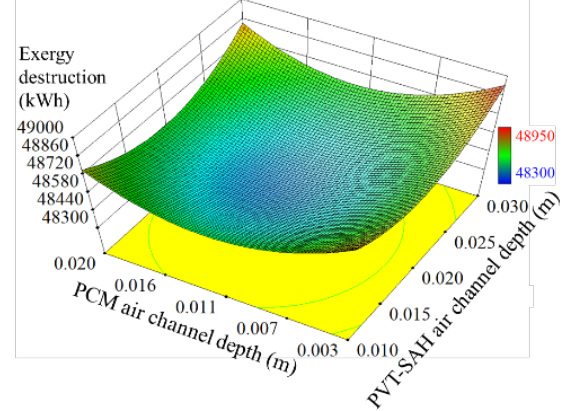

m) $\mathrm{C} \times \mathrm{E}$

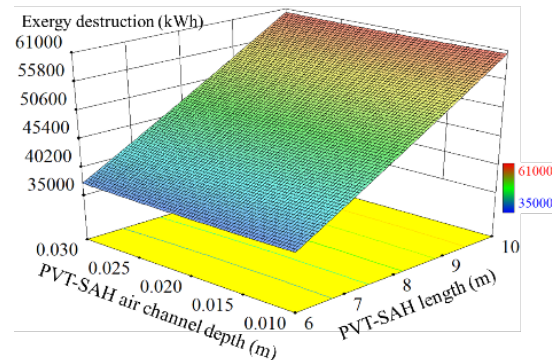

b) $\mathrm{A} \times \mathrm{C}$

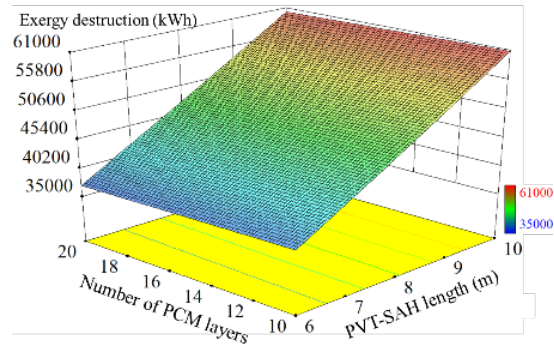

e) $\mathrm{A} \times \mathrm{F}$

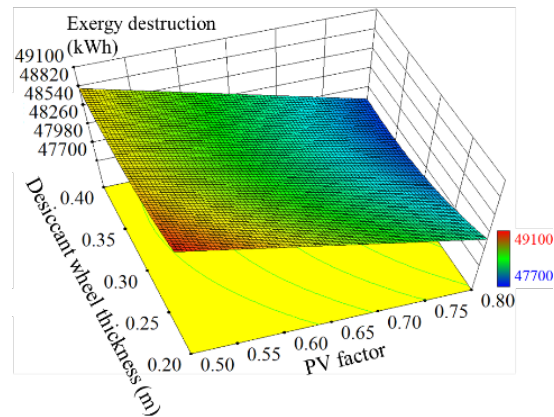

h) $B \times D$

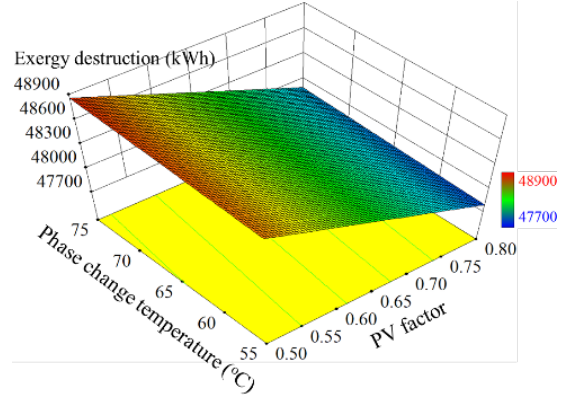

k) $B \times G$

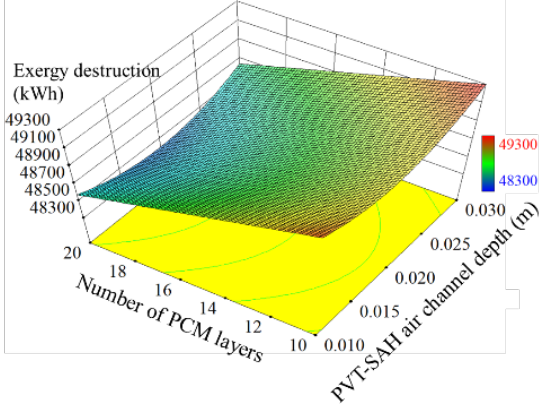

n) $\mathrm{C} \times \mathrm{F}$

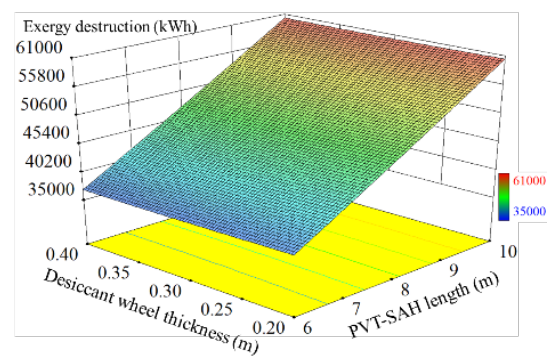

c) $\mathrm{A} \times \mathrm{D}$

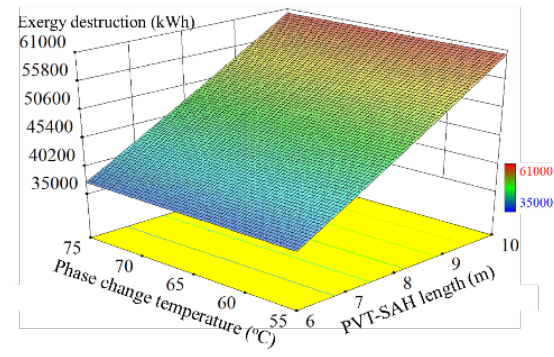

f) $A \times G$

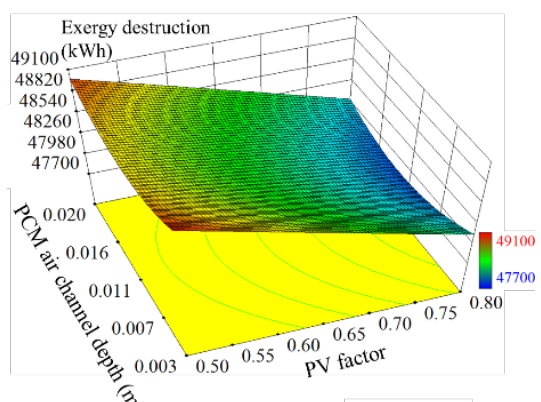

3

i) $\mathrm{B} \times \mathrm{E}$

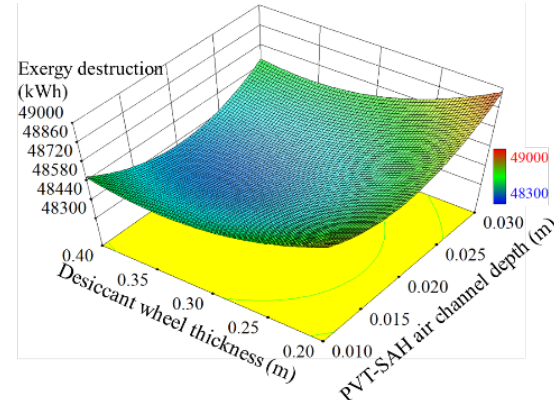

l) $C \times D$

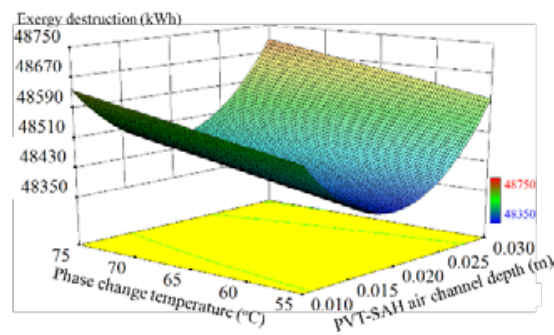

o) $\mathrm{C} \times \mathrm{G}$ 


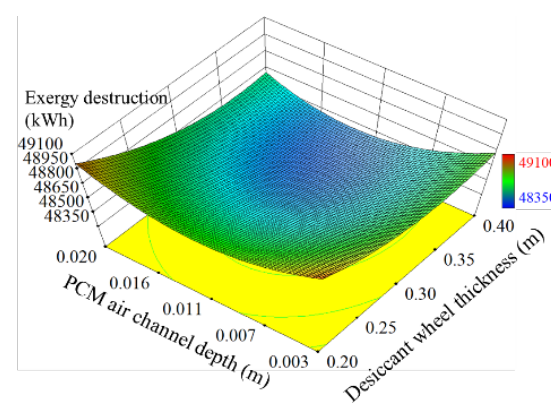

p) $\mathrm{D} \times \mathrm{E}$

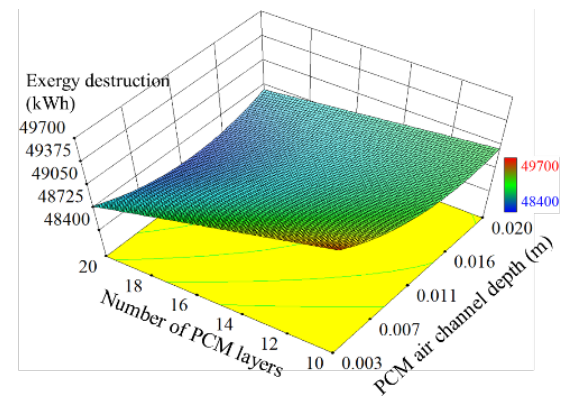

s) $\mathrm{E} \times \mathrm{F}$

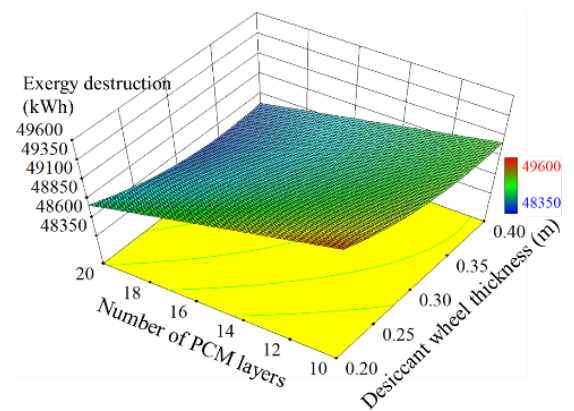

q) $\mathrm{D} \times \mathrm{F}$

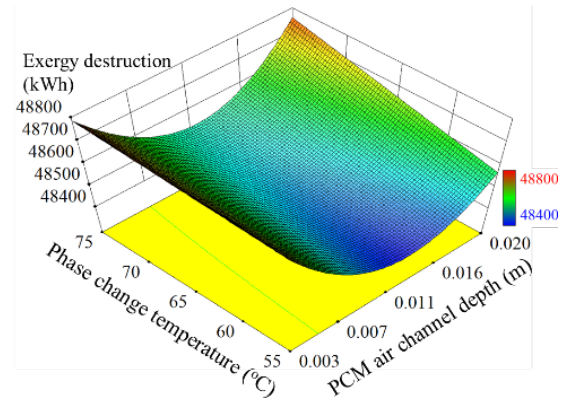

t) $E \times G$

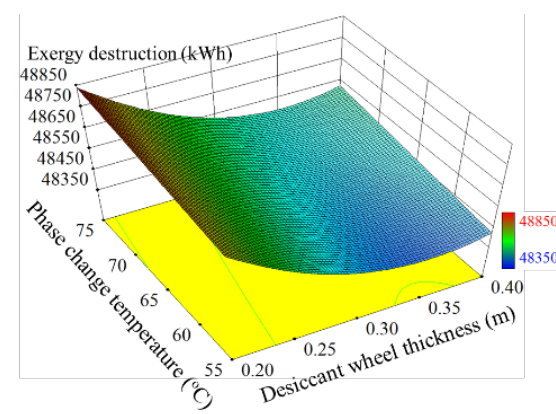

r) $\mathrm{D} \times \mathrm{G}$

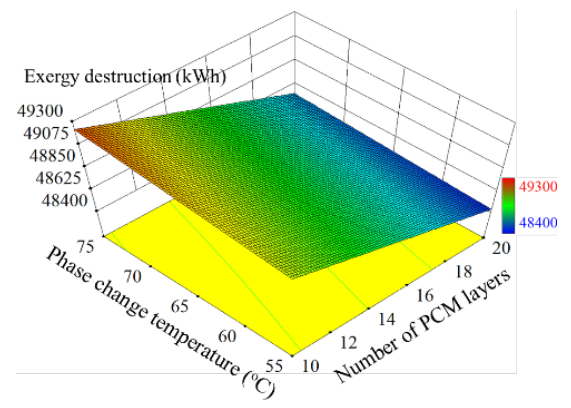

u) $\mathrm{F} \times \mathrm{G}$

Fig. 10. Variations of total exergy destruction with the change of seven key design parameters (A - PV/T-SAC length; B - PV factor; C - PV/T-SAC air channel depth; D - DW thickness; E PCM TES unit air channel depth; F - number of PCM layers; and G - PCM phase change temperature). 